\title{
Hard-Site $\kappa_{0}$ (Kappa) Calculations for Christchurch, New Zealand, and Comparison with Local Ground-Motion Prediction Models
}

\author{
by Chris Van Houtte, Olga-Joan Ktenidou, Tam Larkin, and Caroline Holden
}

\begin{abstract}
The 2010-2012 Canterbury earthquake sequence generated a large number of near-source earthquake recordings, with the vast majority of large events occurring within $30 \mathrm{~km}$ of Christchurch, New Zealand's second largest city. We utilize the dataset to estimate the site attenuation parameter, $\kappa_{0}$, at seven rock and stiff-soil stations in New Zealand's GeoNet seismic network. As part of this study, an orientationindependent definition of $\kappa$ is proposed to minimize the influence of observed highfrequency 2D site effects. Minimum magnitude limits for the traditional high-frequency fitting method are proposed, based on the effect of the source corner frequency. A dependence of $\kappa_{0}$ on ground-shaking level is also observed, in which events with large peak ground accelerations (PGAs) have lower $\kappa_{0}$ values than events with small PGAs. This observation is not fully understood, but if such a trend holds in future investigations, it may influence how $\kappa_{0}$ is used in hazard assessments for critical facilities. $\kappa_{0}$ values calculated from Fourier amplitude spectra of acceleration $\left(\kappa_{0, \mathrm{AS}}\right)$ are compared with the native $\kappa_{0}$ of local, empirical, ground-motion prediction equations (GMPEs), calculated using the inverse random vibration theory method $\left(\kappa_{0, \mathrm{IRVT}}\right)$. $\kappa_{0, \text { IRVT }}$ is found to be independent of magnitude and distance and agrees with the average $\kappa_{0, \mathrm{AS}}$ for the region. $\kappa_{0, \mathrm{IRVT}}$ does not scale strongly with $V_{S 30}$, indicating that current GMPEs may be capturing the average kappa effect through the $V_{S 30}$ scaling. The results from this study are of particular interest for site-specific ground-motion prediction studies as well as for GMPE adjustments between different regions or rock types.
\end{abstract}

\section{Introduction}

The Canterbury earthquake sequence began with the $M_{\mathrm{w}} 7.1$ Darfield earthquake on 3 September 2010, and, since then, over 11,000 aftershocks have been recorded (Bannister and Gledhill, 2012). The majority of the events were in close proximity to Christchurch, New Zealand's second largest city (population $\sim 377,000$ ), and as a result, an exceptionally large dataset of near-source strong-motion recordings has been collected. This study uses the available data to estimate the spectral decay parameter, kappa ( $\kappa$, Anderson and Hough, 1984). $\kappa$ controls the rate of high-frequency decay of the Fourier amplitude spectrum (FAS) and can be modeled as

$$
A(f)=A_{0} \exp (-\pi \kappa f), \quad f>f_{e},
$$

in which $f_{e}$ is the frequency above which the decay is approximately linear on a plot of log Fourier amplitude versus linear frequency. $\kappa$ is typically considered to be a function of epicentral distance $(R)$ and a site variable $(S)$, mathematically formulated as

$$
\kappa(R, S)=\kappa_{0}(S)+\tilde{\kappa}(R),
$$

in which $\kappa_{0}(S)$ represents the attenuation in the near-surface geology and is specific to every site, and $\tilde{\kappa}(R)$ is the distance dependence of $\kappa$, constrained to equal zero at zero epicentral distance (Anderson, 1991). Although the majority of recent $\kappa$ studies adopt the parameterization in equation (2), the physical interpretation of $\kappa$ has been a contentious issue ever since it was first observed. The pioneering studies that first modeled high-frequency attenuation (Hanks, 1982; Anderson and Hough, 1984) interpreted the high-frequency decay as a site effect (i.e., a sharp increase in attenuation in near-surface layers), whereas others attributed the decay to source effects (e.g., Papageorgiou and Aki, 1983; Aki, 1987). Some more recent studies have suggested there may be both source and site components contributing to the measured $\kappa$ value (e.g., Tsai and Chen, 2000; Purvance and Anderson, 2003); current understanding, however, is that $\kappa$ primarily depends on path and site attenuation.

Under the assumption that it represents site attenuation, $\kappa_{0}(S)$, hereafter referred to as $\kappa_{0}$, has become a widely used parameter in a range of engineering and seismological applications. For some ground-motion simulation codes (e.g., Boore, 2003; Motazedian and Atkinson, 2005), $\kappa_{0}$ is an input 
parameter to model the high-frequency shape of the simulated spectra, by controlling the rate of decay of an exponential low-pass filter applied across the entire frequency band. In conjunction with $V_{S 30}$ (the time-averaged shear-wave velocity in the first $30 \mathrm{~m}$ below ground surface), the $\kappa_{0}$ parameter has recently been used to more accurately model rock-site amplification functions and has been implemented as a predictor variable in an empirical ground-motion prediction equation (GMPE) for rock sites (Laurendeau et al., 2013). For the purposes of site-specific ground-motion prediction, $\kappa_{0}$ is used as a GMPE adjustment parameter in the host-to-target method of Campbell (2003), accounting for regional differences in rock-site attenuation between the host and target regions (Cotton et al., 2006; Douglas et al., 2006; Van Houtte et al., 2011).

Recently, the question has been raised, how should $\kappa_{0}$ be estimated for each of these applications? Several different measurement methods exist, which are not necessarily equivalent to each other. Ktenidou et al. (2014) identified different approaches to measure $\kappa_{0}$ and grouped them into families based on consistency: (1) the high-frequency family, in which $\kappa$ is measured on the high-frequency part of the data, then an extrapolation to zero distance is made to derive $\kappa_{0}$ and (2) the broadband family, in which $\kappa_{0}$ is derived as one of a set of parameters over the entire frequency band. These authors also introduced the notion that these families may be better suited to different applications. They suggest that a $\kappa_{0}$ value derived across the entire frequency band may be more suitable to use as an input in stochastic simulations, whereas a $\kappa_{0}$ measured only on the high-frequency part of the data may be better suited for empirical ground-motion prediction. This paper is concerned with GMPE adjustments and the high-frequency family of $\kappa$ estimation methods.

$\kappa_{0}$ scaling (i.e., applying adjustment factors to a GMPE to account for site or regional differences in $\kappa_{0}$ effects) is currently a challenging task (e.g., Biro and Renault, 2012). Although a representative $\kappa_{0}$ value for the host GMPE's dataset can be directly measured using an inverse random vibration theory (IRVT) approach $\left(\kappa_{0, \mathrm{IRVT}}, \mathrm{Al}\right.$ Atik et al., 2014), this method is not applicable for a low-seismicity target region, where local, empirically derived GMPEs are typically unavailable. Direct measurement of a representative $\kappa_{0}$ value in the target region is inherently difficult, given a general lack of data. The typical alternative is inference of $\kappa_{0}$ from correlations with $V_{S 30}$ (Silva et al., 1998; Chandler et al., 2006; Edwards et al., 2011; Van Houtte et al., 2011; Edwards and Fäh, 2013). The overall correlation of $\kappa_{0}$ with $V_{S 30}$ is poor, with different studies yielding significantly different results, especially for rock sites. This makes inferring a representative $\kappa_{0}$ value for the target region difficult and unreliable. In this study, we examine ways to improve the robustness of target region $\kappa_{0}$ estimates, particularly by measuring $\kappa_{0}$ directly from local small magnitude data.

Aside from the uncertainties that stem from the different methods used to estimate $\kappa_{0}$ across different studies, there is also considerable uncertainty due to the variability of $\kappa$ mea- surements within a single study. Most studies identify significant scatter between their calculated $\kappa$ results and the parameterization in equation (2). This has facilitated the debate regarding the physical mechanism causing $\kappa$. Kilb et al. (2012) speculate that the scatter is due to a combination of physical parameters such as focal mechanism, near-source path effects, and near-surface heterogeneities. Ktenidou et al. (2013) examined the variability arising from different assumptions in the computational process (e.g., choice of distance metric, correction for site amplification, signal-tonoise ratio [SNR]) and offered guidelines for a more robust computational process. Despite their standardized computation process, the variability in obtained $\kappa$ measurements was still substantial. This raises the question, what is causing the scatter of $\kappa$ measurements?

The first motivation of this study is to identify sources of scatter in $\kappa$ measurements from FAS of acceleration (i.e., $\kappa_{\mathrm{AS}}$ ) and provide recommendations for computing more stable values in future studies. The second aim of the article is to compare measured $\kappa_{0, \mathrm{AS}}$ estimates from Christchurch with $\kappa_{0, \text { IRVT }}$ from local ground-motion prediction models and to investigate whether these two methods for calculating $\kappa_{0}$ are consistent. Both methods belong to the high-frequency family of methods suitable for GMPE adjustments.

\section{Data}

The dataset used for this study comprises events recorded at seven GeoNet rock and stiff-soil stations (AKSS, CRLZ, D14C, GODS, HVSC, MQZ, and MTPS; see Data and Resources) from the Canterbury region in the South Island of New Zealand. All are free-field, surface stations, except for CRLZ, which is located in a cavern approximately $30 \mathrm{~m}$ below ground surface. The locations of these stations are shown in Figure 1. The sites have been previously characterized in terms of resonant site period using the horizontal-to-vertical spectral ratio (HVSR) method for $S$-wave shaking (Van Houtte et al., 2012). In addition, approximate shear-wave velocity profiles were obtained via geophysical investigations as part of this study. With only vertical geophones available, the geophysical investigation techniques were limited to $P$-wave and Rayleigh-wave analyses. The Rayleigh-wave analysis was limited to high frequencies (greater than $14 \mathrm{~Hz}$ ), hence the penetration depth typically reached only 10-20 m. Therefore, it must be noted that the $V_{S 30}$ values used in this study are partially inferred, based on the assumption that the $V_{S}$ of the bedrock is constant down to $30 \mathrm{~m}$. For the MQZ station, no $V_{S}$ measurements were possible, hence the $V_{S 30}$ value of $1000 \mathrm{~m} / \mathrm{s}$ is inferred based on correlations with geological data in the region. HVSC has been previously characterized by Wood et al. (2011), and we adopt their profile for this study. Table 1 shows all site information available for each station in this study, including resonant frequencies, newly assessed $V_{S 30}$ values, and NZS1170.5:2004 site classifications (Standards New Zealand, 2004). 


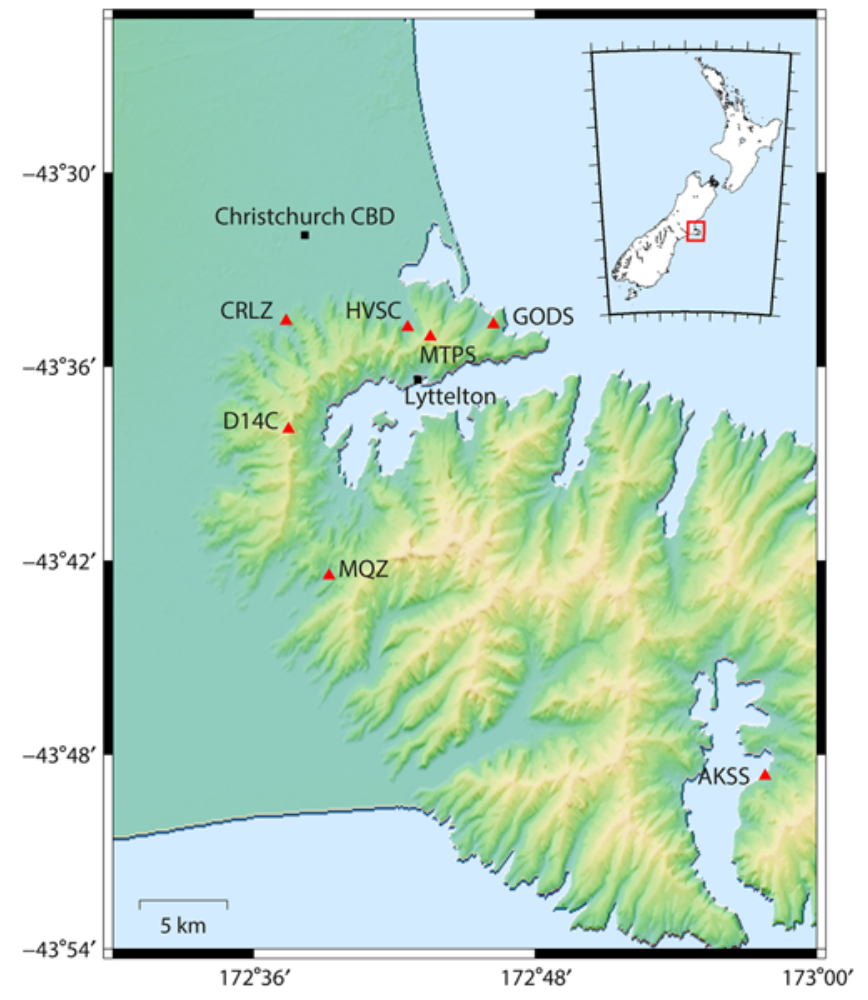

Figure 1. Locations of the seismic stations analyzed in this study. The color version of this figure is available only in the electronic edition.

Two stations (CRLZ and MQZ) comprise both a strongmotion accelerometer and a co-located broadband velocity sensor, whereas AKSS, D14C, GODS, HVSC, and MTPS are strong-motion accelerometers. The accelerometer at MQZ samples at $50 \mathrm{~Hz}$, whereas the remaining strong-motion instruments sample at $200 \mathrm{~Hz}$. The large number of near-source recordings from the Canterbury earthquake sequence enables us to work with the subset of records at epicentral distance $(R)$ less than $30 \mathrm{~km}$. This allows us to neglect any path dependence of $\kappa$, that is, the $\tilde{\kappa}(R)$ term in equation (2), and assume that each individual measured $\kappa$ value from an event with epicentral distance less than $30 \mathrm{~km}$ corresponds to a zerodistance $\kappa_{0}$ value, similar to Rebollar (1990) and Kilb et al.
(2012). We justify using this assumption in the Distance Dependence of $\kappa_{\mathrm{AS}}$ section. Therefore, we obtained a dataset of 508 accelerograms recorded at the seven stations, of which 424 have $R<30 \mathrm{~km}$.

Broadband velocity instruments tend to have a smaller usable frequency range than modern accelerometers. Both of the two stations with co-located broadband instruments (CRLZ and MQZ) sample at $100 \mathrm{~Hz}$, and after correction for instrument response, the passband (i.e., unity gain) for these instruments is approximately $1-40 \mathrm{~Hz}$. However, the CRLZ site exhibits strong high-frequency site amplification and deamplification effects due to its location in a cavern (Van Houtte et al., 2012), which renders measuring $\kappa$ unreliable in this passband. We therefore discard the velocity channel of CRLZ and only consider the acceleration channel, which has a higher maximum usable frequency $(>70 \mathrm{~Hz})$. The greater passband for the CRLZ accelerometer enables measurement of $\kappa$ at frequencies higher than that of the site effects. Thus, MQZ has the only available broadband instrument to robustly measure $\kappa$ for small magnitude events, and from this station we obtain 1655 events, of which 1099 have epicentral distances less than $30 \mathrm{~km}$. Table 1 shows the total number of recordings at each station, instrument types, and their sampling rates. A magnitude-distance plot of the dataset is shown in Figure 2. The four largest events have published moment magnitude $\left(M_{\mathrm{w}}\right)$ estimates, whereas the smaller events have been converted from GeoNet local magnitudes $\left(M_{\mathrm{L}}\right.$; Haines, 1981) to $M_{\mathrm{w}}$ using the correlation of Ristau (2013). An issue with using the Ristau (2013) $M_{\mathrm{L}}-M_{\mathrm{w}}$ relationship is that only events with $M_{\mathrm{w}}>3$ were used to create the correlation, whereas our dataset contains many events with $M_{\mathrm{w}}<3$. Although it is unclear whether the relationship will hold for $M_{\mathrm{w}}<3$, we have no definitive evidence to the contrary, and using it is unlikely to introduce significant bias to the results. Therefore, we extrapolate and apply the $M_{\mathrm{L}}-M_{\mathrm{w}}$ correlation to all events in the dataset.

All earthquakes analyzed in this study have focal depths less than $15 \mathrm{~km}$. Metadata for the fine-scale relocations of events are from Bannister et al. (2011). The key advantage of the dataset is the good coverage of events across a widemagnitude range at near-source distances, which allows us to

Table 1

GeoNet Sites in This Study

\begin{tabular}{lccccrr}
\hline Station & $\begin{array}{c}\text { Sampling } \\
\text { Rate }(\mathrm{Hz})\end{array}$ & $V_{S 30}(\mathrm{~m} / \mathrm{s})$ & $\begin{array}{c}\text { Fundamental } \\
\text { Frequency }(\mathrm{Hz})\end{array}$ & $\begin{array}{c}\text { NZS1170.5: 2004 } \\
\text { Site Class }\end{array}$ & $\begin{array}{c}\text { Total } \\
\text { Recordings }\end{array}$ & $\begin{array}{c}\text { Recordings with } \\
R_{e}<30 \mathrm{~km}\end{array}$ \\
\hline AKSS & 200 & 1073 & 9 & $\mathrm{~B}$ & 46 & 11 \\
CRLZ & 200 & 900 & 1 & $\mathrm{~B}$ & 143 & 124 \\
D14C & 200 & 733 & 1 & $\mathrm{~B}$ & 84 & 70 \\
GODS & 200 & 586 & 1 & $\mathrm{~B}$ & 106 & 99 \\
HVSC & 200 & 422 & 3.5 & $\mathrm{C}$ & 34 & 33 \\
MQZ & 100 & $1000^{*}$ & 8 & $\mathrm{~B}$ & 1655 & 1099 \\
MTPS & 200 & 830 & 1 & $\mathrm{~B}$ & 95 & 87 \\
\hline
\end{tabular}

All instruments are strong-motion accelerometers, except MQZ, which is a broadband instrument.

$* V_{S 30}$ for this station is entirely inferred. 


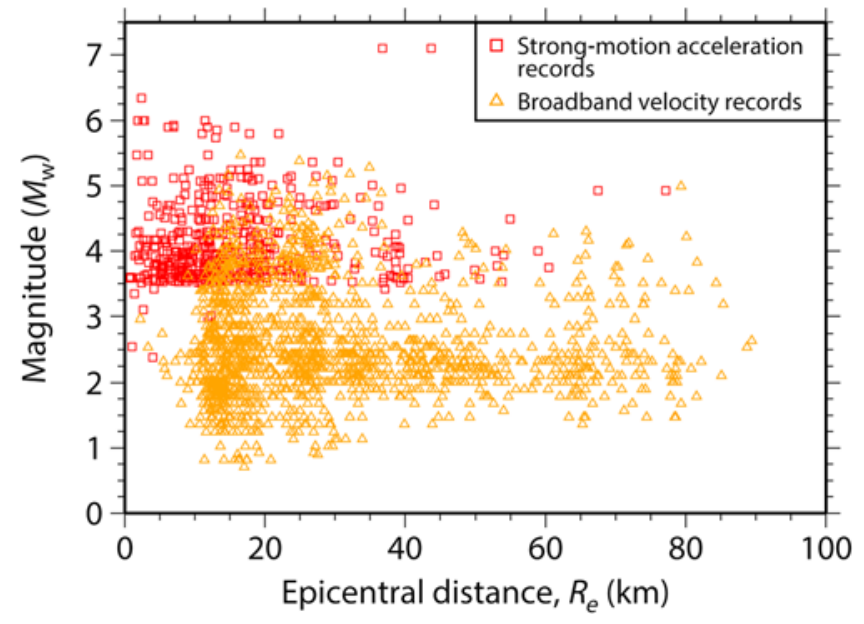

Figure 2. Magnitude-epicentral distance distribution of events analyzed in this study. Squares indicate events recorded by strongmotion stations and triangles indicate events recorded by a broadband sensor. The color version of this figure is available only in the electronic edition.

empirically investigate the sensitivity of $\kappa_{0, \mathrm{AS}}$ estimates to magnitude and distance.

\section{Method}

\section{Data Processing and Calculation of $\kappa_{\mathrm{AS}}$}

For each recording in the dataset, the waveforms were baseline corrected, the instrument response was removed, the data were converted to units of acceleration (where applicable), and then time windows for $S$-wave shaking and preevent noise were selected. Signal windows were selected to encapsulate the main portion of $S$-wave shaking, with a fixed window duration of five seconds. Noise windows were selected either from pre-event noise or, if this was unavailable, from the last part of the trace to minimize any wave reflections in the noise window. Both signal and noise windows were 5\% cosine tapered at both edges and Fourier transformed. Only amplitudes (i.e., FAS) were retained for the analysis.

We use the Anderson and Hough (1984) method to estimate $\kappa$ directly on the high-frequency part of FAS $\left(\kappa_{\mathrm{AS}}\right)$. This method was selected based on its relevance for the host-to-target method for empirical GMPE adjustments. The process we follow is based on the recommended procedure of Ktenidou et al. (2013), in terms of accounting for source corner frequency $\left(f_{\mathrm{c}}\right)$, SNR, and minimum usable frequency range. As a first step, $f_{\mathrm{c}}$ was manually picked from displacement spectra. The lower bound of the high-frequency slope, $f_{e}$, was selected to always be higher than $f_{\mathrm{c}}$, to avoid any source effects on the frequency band used to estimate $\kappa_{\mathrm{AS}}$. The upper bound, $f_{x}$, was defined as the smallest of the following: (1) the frequency at which three times the level of noise exceeds the signal (i.e., SNR > 3), (2) the point at which the high-frequency slope clearly plateaus, or (3) the maximum usable frequency of data from the particular instrument (e.g., $80 \%$ of the Nyquist frequency or maximum value of flat instrument response). The site response for each station was also considered in the selection of $f_{e}$ and $f_{x}$, using the HVSRs from recorded earthquake motions obtained in Van Houtte et al. (2012), as any amplification or deamplification effects in the chosen frequency band can adversely affect $\kappa$ measurements (Parolai and Bindi, 2004). In the interest of robustness, a minimum $\Delta f$ (i.e., $f_{x}-f_{e}$ ) of $10 \mathrm{~Hz}$ was applied.

Figure 3a,b,c shows an example of $S$-wave and noise time windows, FAS, and picks of $f_{\mathrm{c}}, f_{e}$, and $f_{x}$, respectively, for an event in the Canterbury sequence. In this study, only $\kappa$ measurements for horizontal shaking are analyzed, and the vertical component is not considered.

\section{Orientation-Independent $\kappa_{\mathrm{AS}}$ Definition}

Thus far, we have detailed a method to compute $\kappa_{\mathrm{AS}}$ from a single earthquake FAS, that is, one horizontal component of motion. In several previous studies, $\kappa_{\mathrm{AS}}$ is measured on each of the two horizontal components using a similar method to that described here, then averaged to obtain one $\kappa_{\mathrm{AS}}$ value per station per event (Douglas et al., 2010; Gentili and Franceschina, 2011; Van Houtte et al., 2011; Ktenidou et al., 2013). Some of these studies also apply criteria that reject data the $\kappa_{\mathrm{AS}}$ values of which differ greatly between the two components (Van Houtte et al., 2011; Ktenidou et al., 2013). Given that such rejection criteria are somewhat arbitrary and may bias results, we investigate whether the orientation of the two horizontal components affects $\kappa_{\mathrm{AS}}$ measurements, using the accelometric data from events at less than $30 \mathrm{~km}$ epicentral distance. For each triaxial recording, the two horizontal components are rotated at $5^{\circ}$ increments through $90^{\circ}$, giving a total of 36 individual time series per station per event. $\kappa$ is then calculated on each rotation increment of the 36 time series using the method described in the Data Processing and Calculation of $\kappa_{\mathrm{AS}}$ section (with $f_{e}$ and $f_{x}$ fixed for all 36 spectra).

In Figure 4, each line of data points represents $\kappa_{\mathrm{AS}}$ results for one station, as the horizontal components are rotated. Each data point shows the average value of $\kappa_{\mathrm{AS}}$, averaged over all events at that station, for the specific orientation of the sensor. Orientations are shown on the $x$ axis in $5^{\circ}$ increments, first for the north component (from $0^{\circ}$ to $85^{\circ}$ ) and then for the east component (from $90^{\circ}$ to $175^{\circ}$ ). As we are examining a mean $\kappa_{\mathrm{AS}}$ value of all recordings, and the recordings at each station have a wide range of event-to-station azimuths, we assume that any variation in $\kappa_{\mathrm{AS}}$ with component orientation is a local effect, rather than relating to event azimuth. Although the AKSS, CRLZ, and MTPS stations show little variation in $\kappa_{\mathrm{AS}}$ with component orientation, the D14C, GODS, HVSC, and MQZ stations show large differences (approximately $20 \%$ and $25 \%$ between minimum and maximum at GODS and MQZ, respectively). Particularly strong topographic site effects have already been observed at the GODS station on the $\mathrm{N} 150^{\circ}$ component (Van Houtte et al., 2012), and this orientation of the horizontal component corresponds to the maximum average $\kappa_{\mathrm{AS}}$ measurement. This may be an indication that in the 


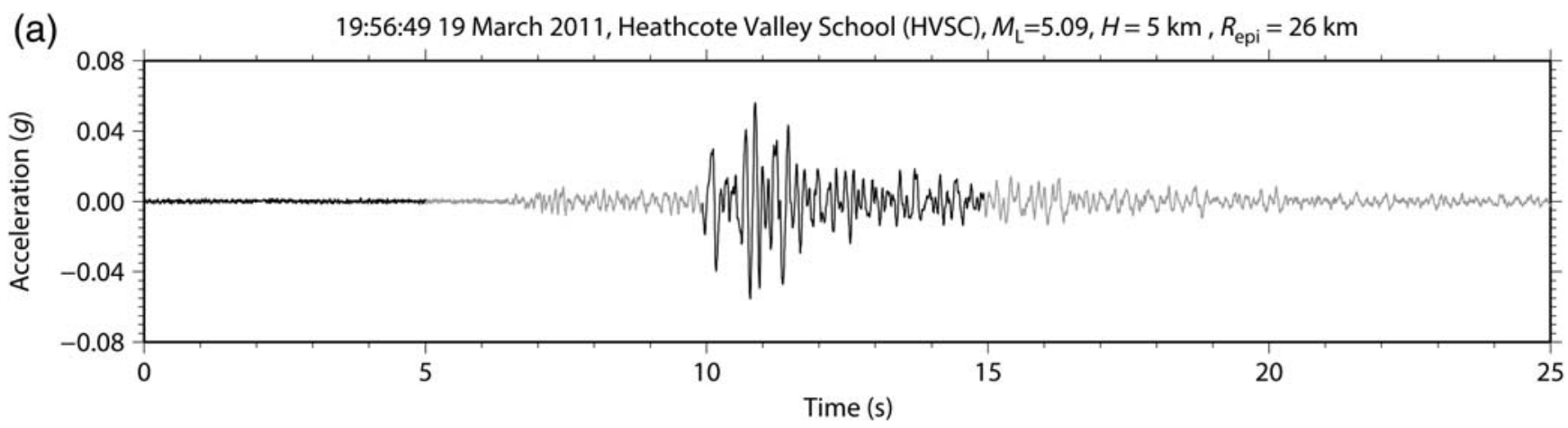

(b)

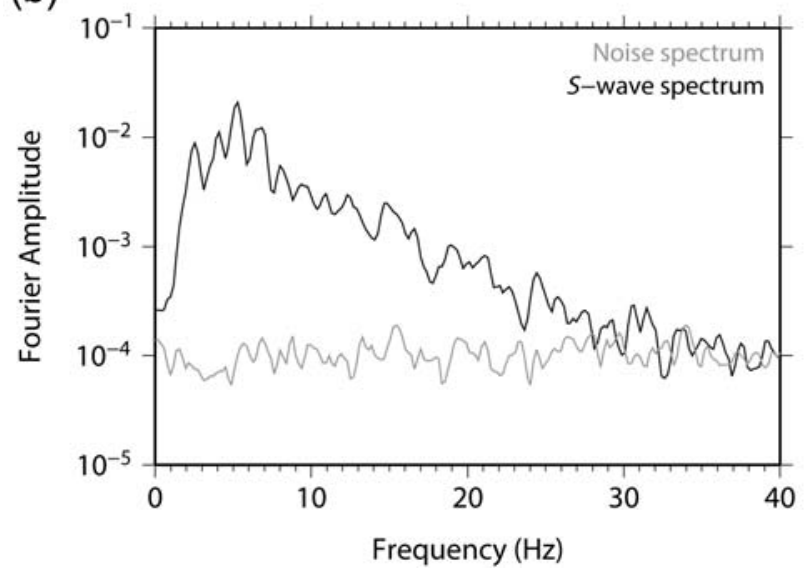

(c)

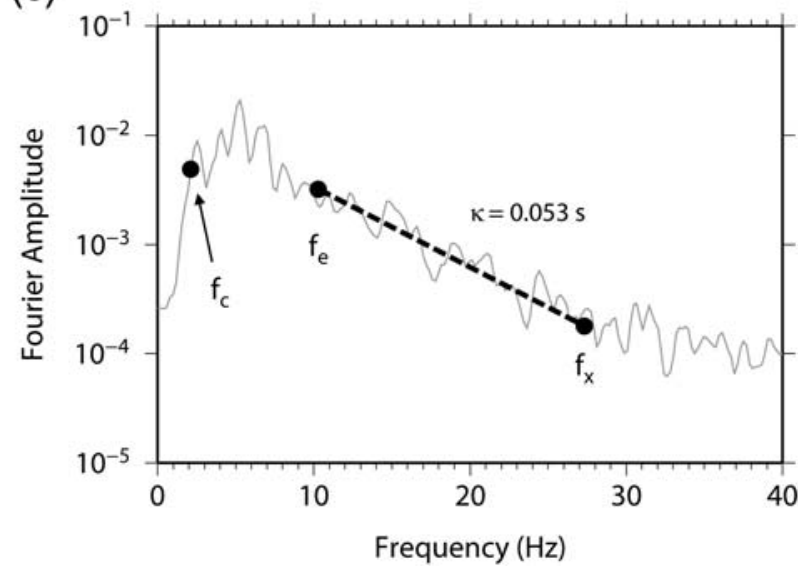

Figure 3. (a) Example $S$ wave and pre-event noise windows from an event in the Canterbury earthquake sequence (indicated in black), (b) their corresponding Fourier amplitude spectra, and (c) $f_{\mathrm{c}}, f_{e}$, and $f_{x}$ picks for calculating $\kappa_{\mathrm{AS}}$. Fourier amplitude units in (b) and (c) are $\mathrm{m} /(9.81 \mathrm{~s})$.

frequency band of measurement (roughly $12-30 \mathrm{~Hz}$ ), 2D site effects may still interfere with $\kappa_{\mathrm{AS}}$ measurements.

This highlights the difficulty in separating the effects of site attenuation and site amplification in $\kappa_{\mathrm{AS}}$ measurements. To average over 2D site effects in future $\kappa_{\mathrm{AS}}$ estimates and derive a more robust value, we propose the following orientation-independent approach for measuring $\kappa_{\mathrm{AS}}$ :

1. Obtain the north and east horizontal (i.e., $\theta_{1}=0$ and $\theta_{2}=90^{\circ}$ ) time series for each recorded event and select $S$-wave time windows.

2. Cosine-taper and Fourier transform time windows, then pick $f_{e}$ and $f_{x}$ on the $S$-wave spectra to obtain $\kappa_{\theta}$.

3. Increment the rotation angle $\theta$ by $\Delta \theta$, in which $\Delta \theta_{\min }=5^{\circ}$.

4. Repeat steps 2 and 3 , holding $f_{e}$ and $f_{x}$ constant for each $\kappa_{\theta}$ measurement, until $\theta_{1}=90^{\circ}$ and $\theta_{2}=180^{\circ}$, respectively.

5. Calculate the mean of all the obtained $\kappa_{\theta}$ measurements. The standard deviation of $\kappa_{\theta}$ is a measure of the scatter of $\kappa$ due to component orientation.

This suggested method is more robust than the current practice of calculating $\kappa_{\mathrm{AS}}$ as the average of $\kappa_{\mathrm{AS}}$ measured on two arbitrarily oriented components. We prefer this defini- tion of an orientation-independent mean $\kappa_{\theta}$ value over measuring $\kappa_{\mathrm{AS}}$ from a single orientation-independent FAS (e.g., the quadratic mean spectrum or the Gonella, 1972, rotary spectrum), as our definition also offers a measure of the scatter in $\kappa_{\mathrm{AS}}$ estimates due to component orientation, indicating whether effects such as high-frequency 2D site response may affect the obtained $\kappa$ results. For this study, we adopt the previously discussed data processing techniques to calculate $\kappa_{\mathrm{AS}}$ from the FAS of a single horizontal recording, then use this orientation-independent approach to calculate one value for horizontal $\kappa_{\mathrm{AS}}$ per event per station.

\section{Distance Dependence of $\kappa_{\mathrm{AS}}$}

Using this method, including the orientation-independent definition, we evaluate the distance dependence of $\kappa_{\mathrm{AS}}$ in the Canterbury region. Given that strong-motion stations did not record a sufficient number of events at epicentral distances greater than $30 \mathrm{~km}$ to examine any trends with distance (see Fig. 2), only the velocity channel of the MQZ station is used to assess distance dependence of $\kappa_{\mathrm{AS}}$ in the Canterbury region. Figure 5 a plots $\kappa_{\mathrm{AS}}$ against epicentral distance, $R_{e}$, with squares indicating the mean and standard deviation of $5 \mathrm{~km}$ distance bins. $\kappa_{\mathrm{AS}}$ here represents the mean 


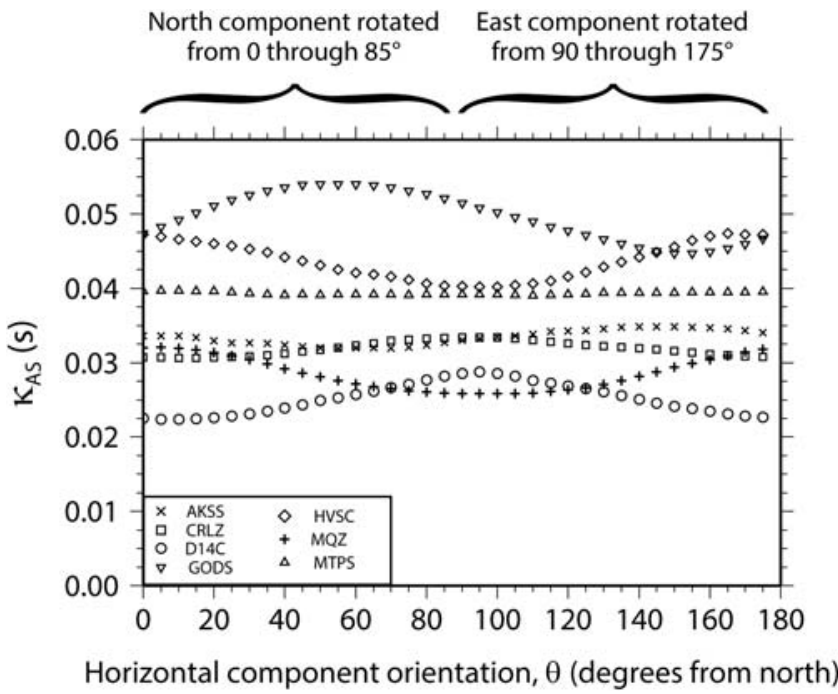

Figure 4. The sensitivity of $\kappa_{\mathrm{AS}}$ measurements to the orientation of the sensor. For every station (see legend), each data point gives the average $\kappa_{\mathrm{AS}}$ for a single component over all events recorded at that station and for the particular orientation of the component. The north component is rotated in $5^{\circ}$ increments from $0^{\circ}$ to $85^{\circ}$ and the east component from $90^{\circ}$ to $175^{\circ}$. For station MTPS the sensitivity of $\kappa_{\mathrm{AS}}$ to sensor orientation is negligible, whereas for station GODS it is substantial.

$\kappa_{\mathrm{AS}}$ of the 36 different horizontal component orientations for each event. Although the scatter is large (as is typical of most $\kappa$ studies), the mean-binned mean $\kappa_{\mathrm{AS}}$ values are relatively constant up to approximately $30-40 \mathrm{~km}$ epicentral distance, above which there is a slight increase in $\kappa_{\mathrm{AS}}$ with distance. This justifies an approximation in which $\kappa_{0, \mathrm{AS}}$ is calculated as an average of all $\kappa_{\mathrm{AS}}$ between 0 and $30 \mathrm{~km}$ epicentral distance.

Figure $5 \mathrm{~b}$ shows the standard deviation of $\kappa_{\mathrm{AS}}$ (i.e., the standard deviation of $\kappa_{\mathrm{AS}}$ from the 36 different horizontal component orientations per event, a measure of the scatter due to component orientation), plotted against epicentral distance. We find the distribution of the standard deviation of $\kappa_{\mathrm{AS}}$ to be lognormal, and the lognormally distributed mean and standard deviation across $5 \mathrm{~km}$ distance bins are indicated as squares in Figure 5b. At epicentral distances less than $20 \mathrm{~km}$, there is a larger scatter for the $\kappa_{\mathrm{AS}}$ estimates due to component orientation. This indicates that, at short distances, finite-fault effects may affect the high-frequency slope, even for small magnitude events. Despite the increased scatter in $\kappa_{\mathrm{AS}}$ estimates, there is no corresponding change in the mean $\kappa_{\mathrm{AS}}$ at distances less than $20 \mathrm{~km}$, hence it is considered that this effect will have little influence on the obtained $\kappa_{0}$ calculations.

\section{Constraints on $\kappa_{\mathrm{AS}}$ Estimation due to Magnitude}

The broadband instrument at the MQZ station recorded a large amount of near-source data across a wide range of magnitudes from 0.5 to 5.5 . This is an unusually wide range and allows us to explore the limitations and applicability of the $\kappa_{\mathrm{AS}}$ approach, which is typically used for large magnitudes. The range of frequencies used to compute $\kappa_{\mathrm{AS}}$ may depend on magnitude, as shown in Ktenidou et al. (2013; see their fig. 4a): the lower the magnitude, the higher the source corner frequency, $f_{\mathrm{c}}$, and the higher the frequency band needed to measure $\kappa_{\mathrm{AS}}$. This frequency band is constrained from below by $f_{\mathrm{c}}$ and from above by the noise level (SNR > 3), instrument sampling rate, and instrument response. Here, we investigate the lowest usable magnitude for determining $\kappa_{\mathrm{AS}}$ given the existing instrument constraints. First, we bin data according to magnitude. In Figure 6a, the dotted lines indicate the boundaries of the magnitude bins, with a similar number of events in each bin. The MQZ velocity channel has a sampling rate of $100 \mathrm{~Hz}$ (Nyquist frequency of $50 \mathrm{~Hz}$ ), and after correction for instrument response, we consider the data to be reliable up to $40 \mathrm{~Hz}$. Adopting this as the upper usable frequency limit of the data, Figure $6 \mathrm{~b}$ shows the $f_{\mathrm{c}}, f_{e}$, and $f_{x}$ values for the data. $f_{\mathrm{c}}$ is only picked for events smaller than magnitude 4 , because it will not pose problems for large magnitudes, for which the $\kappa_{\mathrm{AS}}$ method is well validated. As $f_{\mathrm{c}}$ depends on magnitude, the $f_{e}$ pick must also be magnitude dependent to avoid trade-off between $\kappa_{\mathrm{AS}}$ and source parameters. The $f_{x}$ pick is made visually but is always limited by the maximum usable frequency of $40 \mathrm{~Hz}$, and therefore $\Delta f$ tends to decrease with decreasing magnitude but always remains above $10 \mathrm{~Hz}$. Using these $\Delta f$ ranges, Figure $6 \mathrm{c}$ shows the corresponding $\kappa_{0, \mathrm{AS}}$ values against magnitude, along with the mean and \pm 1 standard deviation of $\kappa_{0, A S}$ per bin. There is no significant magnitude dependence of $\kappa_{0, \mathrm{AS}}$ for magnitudes greater than 2.5 when using these frequency picks. Below this magnitude threshold, the influence of $f_{\mathrm{c}}$ becomes more pronounced, and there is an increasing trade-off between $f_{\mathrm{c}}$ and $\kappa_{0, \mathrm{AS}}$, resulting in a decrease in the mean $\kappa_{0, \mathrm{AS}}$. This decrease indicates an erroneous measurement, as the measured slope no longer solely represents the site attenuation effect.

We now perform a sensitivity analysis on the effect of the maximum usable frequency of the data on $\kappa_{\mathrm{AS}}$ for small magnitudes that is maximum possible $f_{x}$. The maximum possible $f_{x}$ is decreased from 40 to $30 \mathrm{~Hz}$ and $23 \mathrm{~Hz}$, simulating lower sampling rates or different instrument responses. Figure $6 \mathrm{~d}$ compares obtained $\kappa_{0, \mathrm{AS}}$ values for the same dataset, for the different maximum usable frequencies. Only the mean $\kappa_{0, \mathrm{AS}}$ values across the magnitude bins are shown for clarity. When the maximum usable frequency decreases, the tradeoff between $f_{\mathrm{c}}$ and $\kappa_{\mathrm{AS}}$ becomes more evident at larger magnitudes, manifesting as a decrease in measured $\kappa_{0, \mathrm{AS}}$. If the maximum usable frequency is $40 \mathrm{~Hz}, \kappa_{0, \mathrm{AS}}$ cannot be measured reliably for events with magnitude less than 2.5. When the maximum usable frequency is $30 \mathrm{~Hz}, \kappa_{0, \mathrm{AS}}$ measurements should be kept to magnitudes greater than 3 , and if the maximum is $23 \mathrm{~Hz}$ (which may be typical for instruments sampling at $50 \mathrm{~Hz}$ ), the minimum usable magnitude is 3.5 . Above these magnitude thresholds, the data can be used to get good estimates of the mean value of $\kappa_{0, A S}$; however, the standard deviation of the estimates incrementally increases as the 
(a)

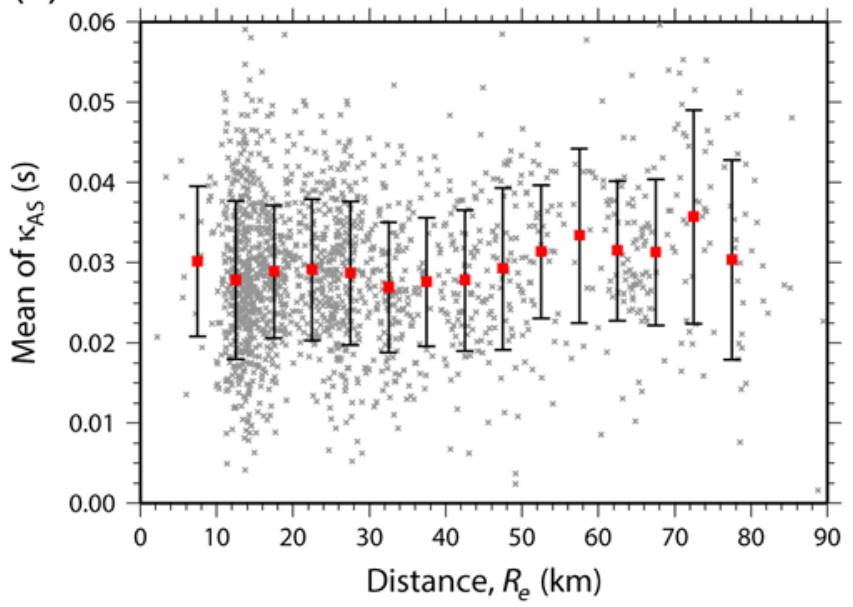

(b)

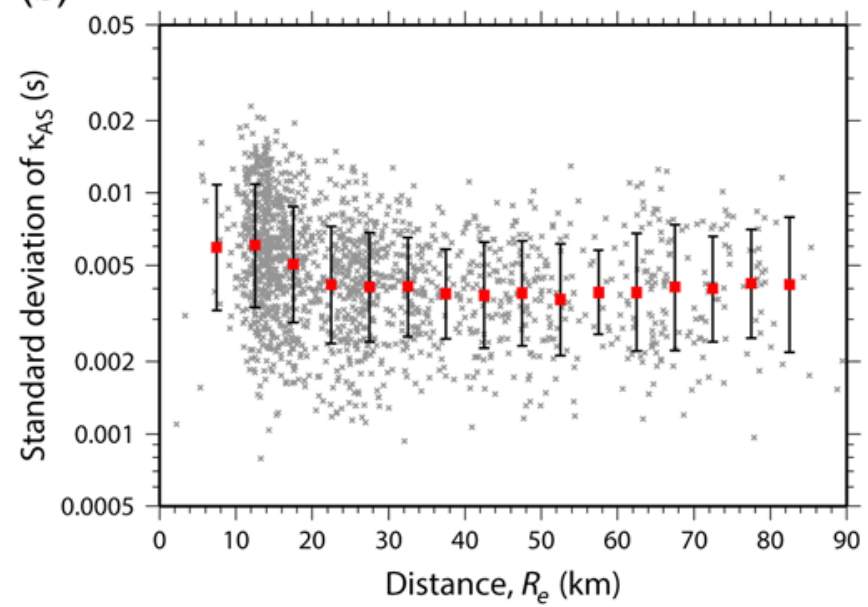

Figure 5. (a) $\kappa_{\mathrm{AS}}$ against epicentral distance, $R_{e}$, for recordings at the MQZ station. Squares indicate the mean of $5 \mathrm{~km}$ distance bins, with error bars representing \pm 1 standard deviation. (b) The standard deviation of $\kappa_{\mathrm{AS}}$ (computed from the normal distribution of the $36 \kappa_{\theta}$ values per event recorded at MQZ), plotted against epicentral distance. Also indicated are lognormally distributed mean and standard deviation of $5 \mathrm{~km}$ distance bins. The color version of this figure is available only in the electronic edition.

maximum usable frequency decreases. To avoid such tradeoffs in future studies, we suggest some magnitude limits for the $\kappa_{\mathrm{AS}}$ method, based on the effects of $f_{\mathrm{c}}$ and maximum usable frequencies of available data. These limits are shown in Table 2. Note that as $\kappa_{\text {AS }}$ increases, the Fourier amplitudes decay more rapidly and may reach the noise level before the maximum usable frequency of the data. The minimum magnitudes indicated in Table 2 assume the $S$-wave Fourier amplitudes are greater than three times the noise amplitudes across the usable frequency band, as was generally the case in this study. In reality, there may be a tendency for the minimum usable magnitude to increase with $\kappa_{\mathrm{AS}}$, and thus the minimum magnitudes in Table 2 should be considered indicative only, and applicable for $\kappa_{\mathrm{AS}} \leq 0.03 \mathrm{~s}$.

A further note from Figure $6 \mathrm{~d}$ is that some error bars for maximum $f_{x}=23$ and $30 \mathrm{~Hz}$ extend to negative $\kappa_{0, \mathrm{AS}}$ values, indicating that many records have $\kappa_{\mathrm{AS}}<0$. This is not observed for any of the data points in Figure $6 \mathrm{c}$, in which the maximum $f_{x}=40 \mathrm{~Hz}$ and highlights the adverse effects of measuring $\kappa_{\mathrm{AS}}$ from data with lower sampling rates.

\section{Correlation with Site Parameters}

$\kappa_{0}$ is commonly assumed to represent the attenuation of seismic waves due to the geology in the upper few kilometers of the Earth's crust. $\kappa_{0}$ is often correlated with $V_{S 30}$, under the assumption that $V_{S 30}$ is indicative of the deeper $V_{S}$ and $Q$ (seismic quality factor) profile that causes the site attenuation. There is considerable scatter in such correlations. Figure 7 a plots the mean $\kappa_{0, \mathrm{As}}$ values for the seven stations analyzed in this study against $V_{S 30}$. The standard deviation of $\kappa_{0, \mathrm{AS}}$ is also indicated. The range of $V_{S 30}$ values and number of stations in the dataset are too small to offer a quantitative correlation; however, it is reasonable to conclude that the softer sites have higher $\kappa_{0, \mathrm{AS}}$ values than the harder sites. $\kappa_{0, \mathrm{AS}}$ still varies significantly (roughly $0.025-0.039 \mathrm{~s}$ ) among the NZS 1170.5:2004 class B sites with similar $V_{S 30}$ values, indicating that $V_{S 30}$ alone cannot be used to accurately infer $\kappa_{0, \text { As }}$.

The average $\kappa_{0, \mathrm{AS}}$ value for rock sites in the region is approximately $0.03 \mathrm{~s}$. However, the error bars indicate large standard deviations ranging from 0.005 to $0.01 \mathrm{~s}$, depending on the station. The standard deviation decreases for harder sites, but again $V_{S 30}$ is not sufficient to describe the variability. Van Houtte et al. (2012) found that several of these sites are located at sites with complex geology, for example, ridges, tunnels, etc., that result in significant 2D response. Hence, in Figure $7 \mathrm{~b}$, we plot the standard deviation of $\kappa_{0, \mathrm{AS}}$ against a simple binary measure of $2 \mathrm{D}$ site effects, in which a value of 1 corresponds to sites with complex 2D geological structures that influence the site response, and a value of 0 is for stations with site response that can be approximated as 1D. The scatter in $\kappa_{0, \mathrm{AS}}$ is significantly higher for stations with strong $2 \mathrm{D}$ site effects, hence 2D site effects may explain some of the variability of $\kappa_{0, \mathrm{AS}}$ measurements, both in this study and in the previous studies on $\kappa$.

\section{Variation with Ground-Motion Amplitude}

The Canterbury earthquake sequence resulted in several rock and stiff-soil recordings with very large horizontal ground-motion amplitudes. This section examines the dependence of $\kappa_{0, \mathrm{AS}}$ with the level of horizontal ground shaking. Figure $8 \mathrm{a}-\mathrm{f}$ plots $\kappa_{0, \mathrm{AS}}$ against peak ground acceleration (PGA) for the six strong-motion stations in this study. Events with large PGAs have smaller values of $\kappa_{0, \mathrm{AS}}$ than small PGA events, particularly evident at the D14C, GODS, HVSC, and MTPS stations. Although the AKSS and CRLZ stations do not show a trend with PGA, all events recorded at these sites had PGAs of less than $0.2 \mathrm{~g}$. PGA is used here to indicate the 
(a)

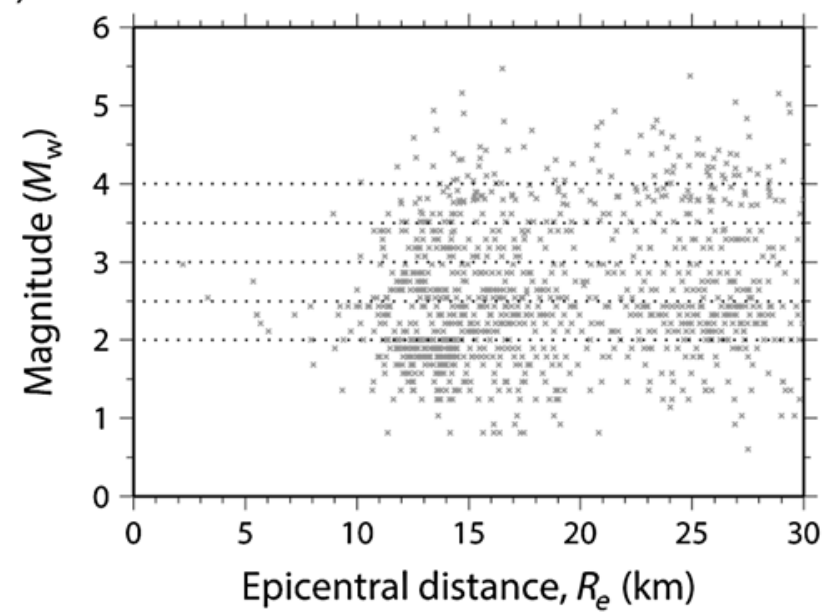

(c)

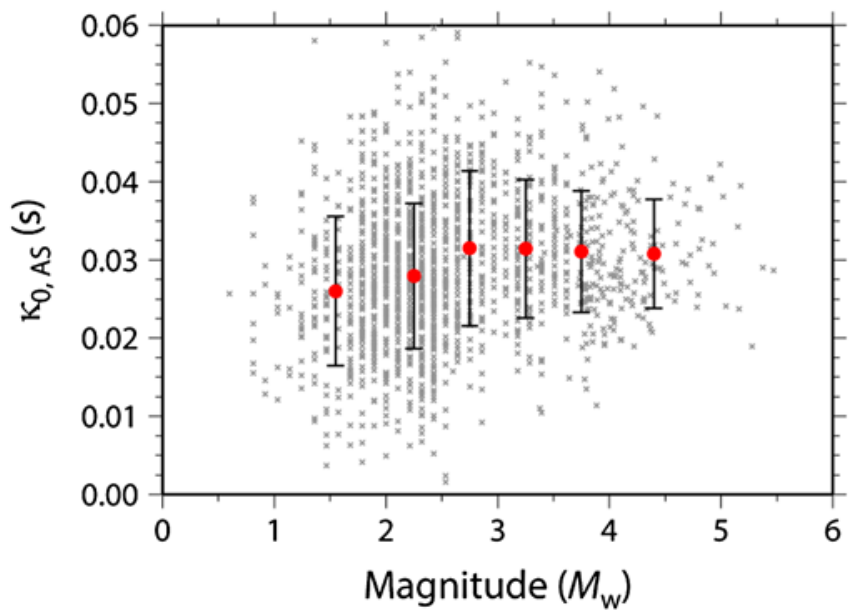

(b)

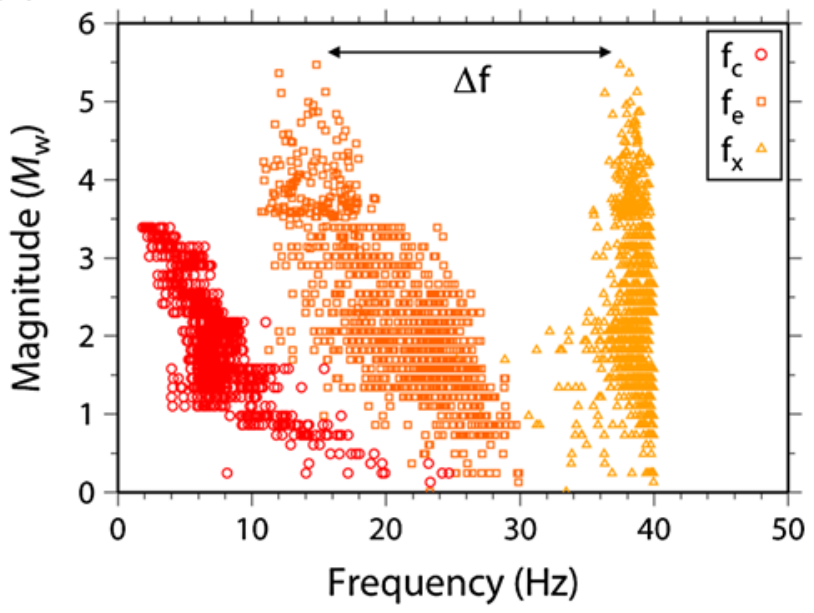

(d)

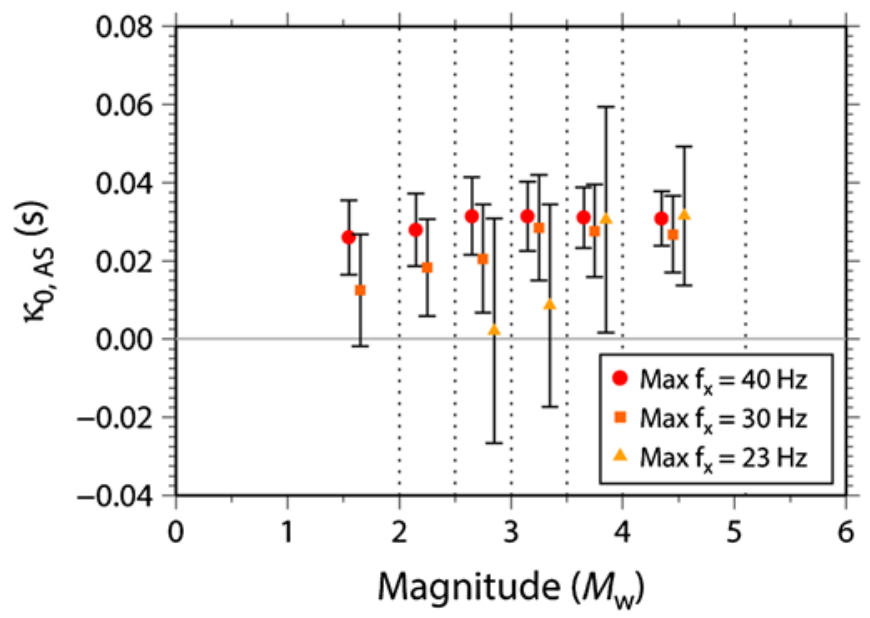

Figure 6. (a) The near-source events recorded by the velocity channel at the MQZ station, with dotted lines indicating the boundaries of magnitude bins that the data are divided into. (b) The distribution of $f_{\mathrm{c}}, f_{e}$, and $f_{x}$ picks with magnitude for the events. (c) $\kappa_{0, \mathrm{AS}}$ against magnitude, with mean of the magnitude bins indicated as circles, with \pm 1 standard deviation indicated by error bars. (d) The effect of the maximum usable frequency of the available data. Note that each bin contains exactly the same data. Only the maximum value for $f_{x}$ has changed. The color version of this figure is available only in the electronic edition.

level of ground shaking (the signal energy), as we observe similar behavior when plotting $\kappa_{0, \mathrm{AS}}$ against all pseudospectral acceleration ordinates.

This is the first time that such a result is reported. To our knowledge, there is only one previous $\kappa$ study that examines dependence with PGA (Dimitriu et al., 2001), which found an increase in $\kappa_{0, \mathrm{AS}}$ with PGA on soft-soil sites. If we

Table 2

Suggested Limits of the Anderson and Hough (1984) Manual-Fitting Method, for $\kappa_{\mathrm{AS}} \leq 0.03 \mathrm{~s}$

\begin{tabular}{cc}
\hline $\begin{array}{c}\text { Maximum Usable Frequency } \\
\text { of Available Data }(\mathrm{Hz})\end{array}$ & $\begin{array}{c}\text { Minimum Magnitude } \\
\text { to Calculate } \kappa_{\mathrm{AS}}\end{array}$ \\
\hline 40 & 2.5 \\
30 & 3 \\
23 & 3.5 \\
\hline
\end{tabular}

consider that part of $\kappa_{0}$ can be seen as damping in the top layers, then it would be expected to increase with the level of shaking if it reached nonlinear soil behavior (as observed in Dimitriu et al., 2001). However, we find the opposite effect here for stiff-soil and soft-rock sites. As we were also unable to attribute the observed variation to a distance effect (the highPGA events did not occur at shorter distances), one possible alternative interpretation is that part of the site attenuation described by $\kappa_{0, \mathrm{AS}}$ may be related to local heterogeneities in the geological profile that cause high-frequency scattering (Faccioli et al., 1989). Under very high-amplitude motion, small-scale heterogeneities in the profile causing such scattering may be smoothed out, leading to a decrease in $\kappa_{0, \mathrm{AS}}$. Furthermore, the wavelengths associated with large amplitude motion may be much longer compared with the dimension of the scatterers. The effects of the decrease in scattering attenuation would need to be greater than the increase in material 

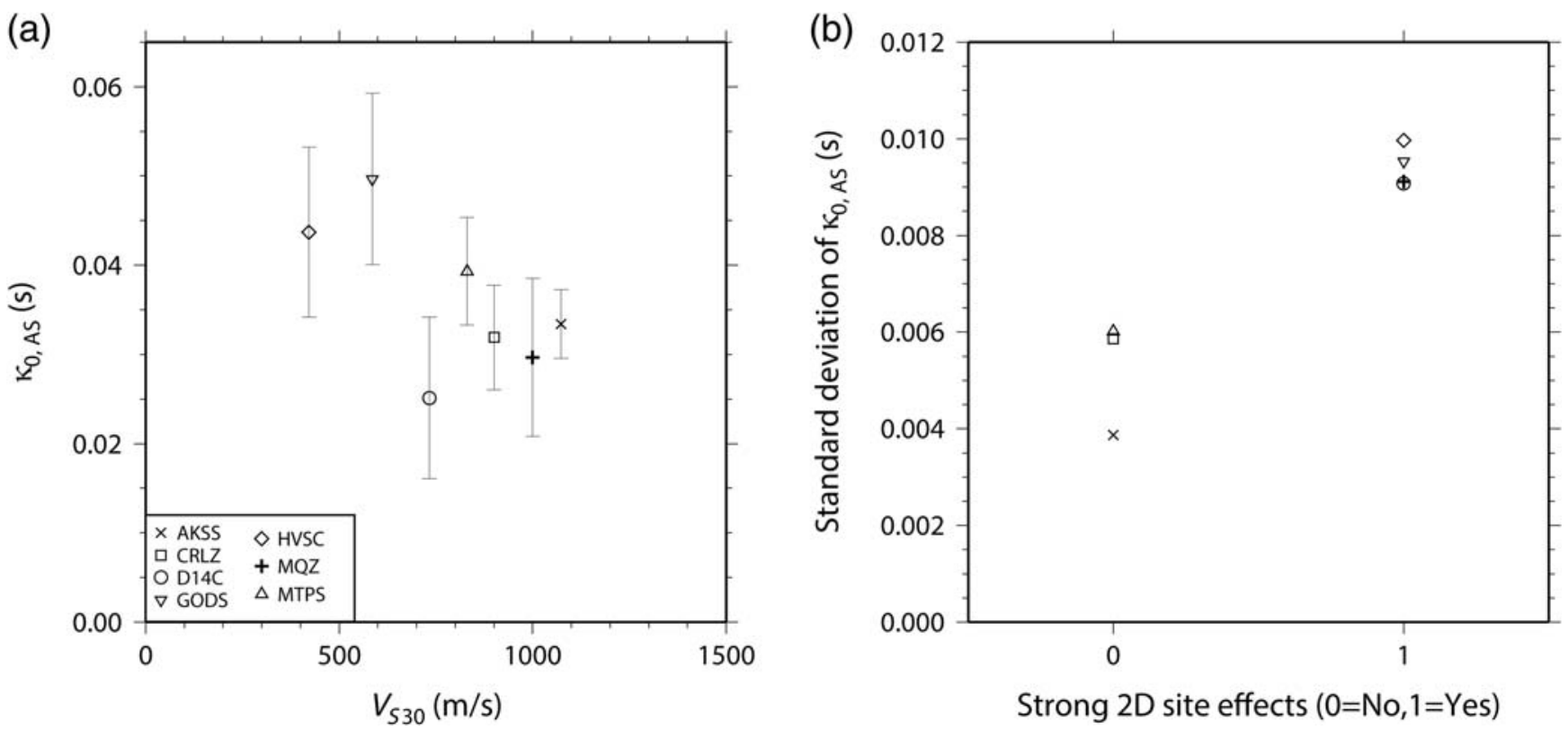

Figure 7. (a) $\kappa_{0, \mathrm{AS}}$ against $V_{S 30}$ for the seven stations in this study. (b) The standard deviation of $\kappa_{0, \mathrm{AS}}$ against a binary measure of $2 \mathrm{D}$ site effects. A value of one corresponds to a site with known strong 2D site effects, whereas a value of zero correponds to a site where the response can be considered 1D.

damping for this interpretation to fit our observations. Another possible explanation for $\kappa_{0, \mathrm{AS}}$ decreasing with PGA is that the correlation is physically representing a dependence with the rate of shear strain, rather than the ground-motion amplitude. Tatsuoka et al. (2008) performed laboratory experiments on the effect of strain rate on damping and found that very high strain rates can actually decrease material damping, and therefore may cause $\kappa_{0}$ to decrease. Note that PGA here is a proxy for strain rate rather than strain amplitude.

These interpretations are only speculative. There are too few data at very high levels of ground shaking for the observation to be statistically significant, and there are no comparable $\kappa$ studies that analyze such large PGAs (even the Dimitriu et al., 2001, study only included one recording with PGA $>0.3 g$ ). However, it might be prudent to consider the possible decrease in $\kappa_{0, \mathrm{AS}}$ with increasing ground-motion amplitude in hazard assessments for important structures, particularly where large, nearby sources make significant contributions to the hazard. Current practice assumes that $\kappa_{0}$ is independent of the level of ground shaking; however, these results suggest that such an assumption may be unconservative. It is possible that these large, nearby events could produce lower values for $\kappa_{0, \mathrm{AS}}$ and therefore increase the seismic hazard at short periods.

\section{Comparison with $\kappa_{0, I R V T}$ from Local GMPEs}

To this point, we studied $\kappa_{0}$ using the Anderson and Hough (1984) approach $\left(\kappa_{0, \mathrm{AS}}\right)$. This section compares these results with the native $\kappa_{0}$ of local empirical GMPEs, calculated using IRVT (Gasparini and Vanmarcke, 1976). These two approaches belong to the high-frequency family of methods, defined by Ktenidou et al. (2014) as being compatible with empirical GMPE adjustments, however, to date no published study has compared the two approaches.

\section{Background}

Given that this is a nascent approach for calculating $\kappa$, here we provide a background to the method. Al Atik et al. (2014) first used IRVT to compute $\kappa_{0}$ from response spectra compatible FAS. The purpose of this approach is to allow a value for $\kappa_{0}$ to be computed from an existing GMPE, representing an average value of $\kappa_{0}$ for the dataset that was used to create the GMPE (hereafter referred to as $\kappa_{0, \mathrm{IRVT}}$ ). The IRVT process is relatively complex and to date is yet to be widely implemented in this context. Although a detailed explanation can be found in Rathje et al. (2005), a simplified summary of the methodology is included here. Using random vibration theory (RVT), the spectral acceleration (SA) is related to the root mean square spectral acceleration $\left(\mathrm{SA}_{\mathrm{rms}}\right)$ by the peak factor $(p)$ :

$$
(\mathrm{SA})^{2}=p^{2}\left(\mathrm{SA}_{\mathrm{rms}}\right)^{2} \text {. }
$$

For a single degree-of-freedom (SDOF) system, $\mathrm{SA}_{\mathrm{rms}}$ can be determined using Parseval's theorem, which states that power is conserved in the time and frequency domains, and thus the total power of a signal can be calculated in either domain:

$$
\left(\mathrm{SA}_{\mathrm{rms}}\right)^{2}=\frac{2}{T_{d}} \int_{0}^{\infty}|A(f)|^{2}\left|H_{f_{n}}(f)\right|^{2} d f,
$$

in which $T_{d}$ is the signal duration, $A(f)$ is the FAS, and $\left|H_{f n}(f)\right|$ is the transfer function of an SDOF oscillator with natural frequency $f_{n}$ and critical damping ratio $\xi$. The difficulty with solving equation (4) is that a given spectral ordinate is 

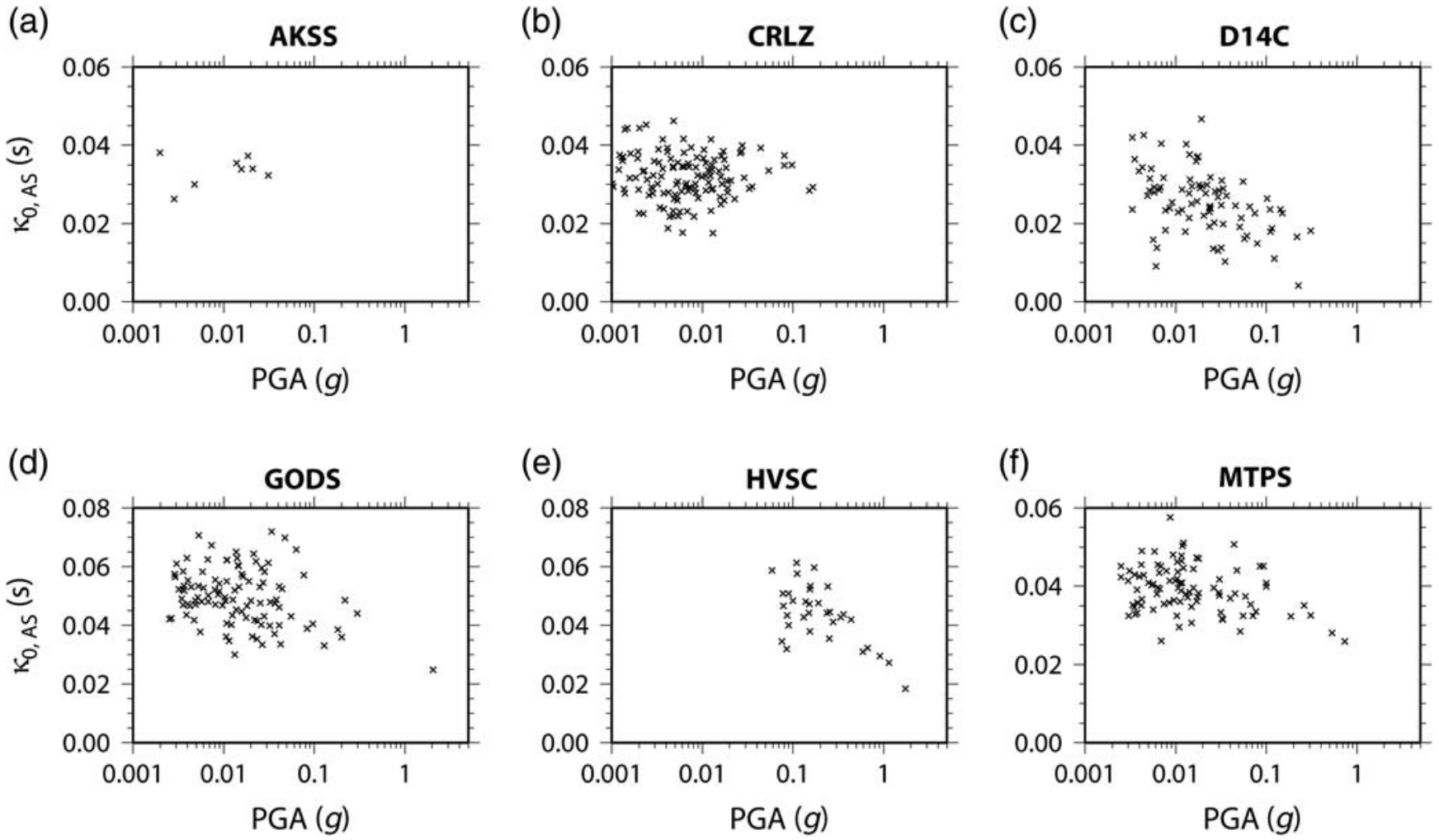

Figure 8. $\kappa_{0, A S}$ against peak ground acceleration for (a) AKSS, (b) CRLZ, (c) D14C, (d) GODS, (e) HVSC, and (f) MTPS strong-motion stations.

influenced by a range of frequencies in the FAS and cannot be used directly to calculate a value in the FAS. To address this issue, the characteristics of lightly damped (e.g., 5\%) SDOF transfer functions are used, namely three important properties: (1) they are equal to unity beneath the natural frequency of the SDOF system, (2) they contain large amplification in a narrowband near the natural frequency, and (3) they quickly tend to zero for frequencies greater than the fundamental frequency. These properties allow the integral in equation (4) to be approximated in terms of the Fourier amplitude at the natural frequency of the oscillator, $\left|A\left(f_{n}\right)\right|$, using a constant value of $|A(f)|^{2}$ equal to its value at the natural frequency. Using the approximated integral, equation (4) is combined with equation (3) to solve for $\left|A\left(f_{n}\right)\right|^{2}$, giving

$$
\left|A\left(f_{n}\right)\right|^{2} \approx \frac{1}{\int_{0}^{\infty}\left|H_{f n}(f)\right|^{2} d f-f_{n}}\left(\frac{T_{d} S_{a}^{2}}{2 p^{2}}-\int_{0}^{f_{n}}|A(f)|^{2} d f\right) .
$$

The integral of the transfer function is constant for a given natural frequency and damping ratio, which simplifies equation (5) to

$$
\left|A\left(f_{n}\right)\right|^{2} \approx \frac{1}{f_{n}\left(\frac{\pi}{4 \xi}-1\right)}\left(\frac{T_{d} S_{a}^{2}}{2 p^{2}}-\int_{0}^{f_{n}}|A(f)|^{2} d f\right) .
$$

Before using equation (6) to invert from a response spectrum to an FAS, an initial estimate of the peak factor $p$ is required. The peak factor depends on the statistical moments of the FAS and the duration of motion and is therefore unknown. By assuming an initial value for $p$, an estimated FAS can be determined and subsquently used for a second calculation of peak factors for the inversion. To calculate the response spectrum compatible FAS, equation (6) is first applied at low frequencies, in which the integral term is approximately equal to zero, then at incrementally higher frequencies. $\kappa$ can then be measured from the obtained FAS in the classic definition of linear high-frequency decay, following Anderson and Hough (1984). To avoid path effects, the input response spectra should be generated for near-source distances (i.e., less than $30 \mathrm{~km}$ ), but not for very small distances (less than $5 \mathrm{~km}$ ), where empirical GMPEs are not well constrained.

\section{Application}

We use the IRVT process to calculate $\kappa_{\text {IRVT }}$ for two New Zealand crustal GMPEs (McVerry et al., 2006; Bradley, 2013). Response spectra are derived using the two GMPEs for various magnitude, distance, and site scenarios, in accordance with Al Atik et al. (2014). For the distance parameter, the McVerry et al. (2006) GMPE uses the closest distance to the rupture plane, $R_{\text {rup }}$, whereas the Bradley (2013) GMPE uses $R_{\text {rup }}$ and the Joyner-Boore distance, $R_{\mathrm{JB}}$. For the site term, Bradley (2013) uses $V_{S 30}$ and depth to bedrock, $Z_{1.0}$, whereas McVerry et al. (2006) use NZS1170.5:2004 site classifications 
(a)

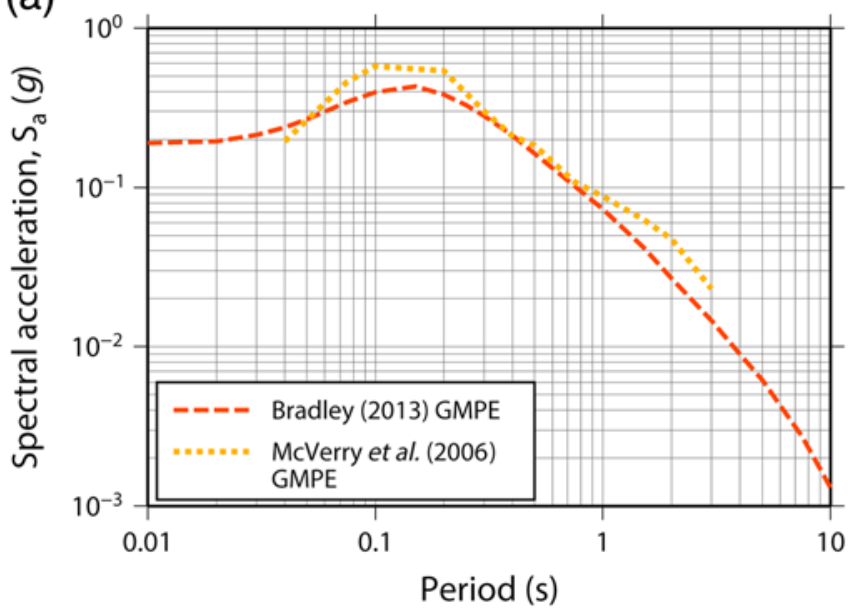

(b)

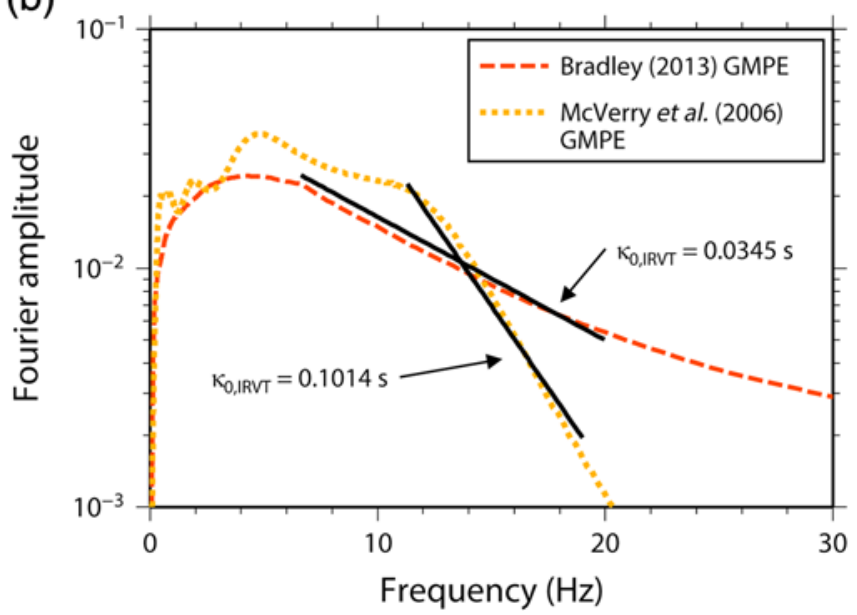

Figure 9. (a) Response spectra for an $M_{\mathrm{w}} 6, R=10 \mathrm{~km}, V_{S 30}=1000 \mathrm{~m} / \mathrm{s}$ scenario using the Bradley (2013) and McVerry et al. (2006) GMPEs and (b) the two compatible FAS calculated using IRVT, with $\kappa_{\text {IRVT }}$ measurements indicated. Note that PGA in the McVerry et al. (2006) GMPE was assumed to represent $T=0.04 \mathrm{~s}$. The color version of this figure is available only in the electronic edition.

(Standards New Zealand, 2004). Both GMPEs are in terms of moment magnitude, $M_{\mathrm{w}}$.

Here, response spectra are generated for vertical strikeslip scenarios with $M_{\mathrm{w}} 5.5,6$, and $6.5, R_{\text {rup }}=5,10,15$, and $20 \mathrm{~km}$, and a fixed hypocentral depth $H=5 \mathrm{~km}$. We infer approximate $R_{\mathrm{JB}}$ values from these parameters, guided by the $R_{\text {rup }}$ and $R_{\mathrm{JB}}$ simulation results from Chiou and Youngs (2006). To calculate the depth to the top of the rupture plane $Z_{\mathrm{TOR}}$, the down-dip rupture width is estimated from $H, M_{\mathrm{w}}$, and focal mechanism, using the relation of Wells and Coppersmith (1994), and $Z_{\mathrm{TOR}}$ is approximated as half the down-dip rupture width, following Scasserra et al. (2009) and Bradley (2013). For these scenarios, we calculate response spectra for each seismic station previously analyzed in this study, using the site information given in Table 1 . Where the depth to bedrock, $Z_{1.0}$, was not directly measured from the geophysical investigations, the $Z_{1.0}$ relationship with $V_{S 30}$ from Chiou and Youngs (2008) was adopted.

Response spectra compatible FAS were then calculated using the IRVT procedure. For the duration input, we use the western United States point-source model (Campbell, 2003) relations:

$$
T_{d}=\frac{1}{f_{\mathrm{c}}}+0.05 R,
$$

in which $f_{\mathrm{c}}$ is the source corner frequency in hertz and $R$ is distance in kilometers. Our estimates of $f_{\mathrm{c}}$ are based on the findings of Oth and Kaiser (2013) for similarly large magnitude events in the Canterbury sequence.

Figure 9a shows the response spectra generated using the Bradley (2013) and McVerry et al. (2006) GMPEs for an $M_{\mathrm{w}} 6, R_{\text {rup }}=10 \mathrm{~km}, V_{S 30}=1000 \mathrm{~m} / \mathrm{s}$ scenario. Figure $9 \mathrm{~b}$ shows the response spectra compatible FAS for this scenario, with a linear slope fitted to the high-frequency decay of each spectrum. As the smallest spectral ordinate in the McVerry et al. (2006) model is at $T=0.075 \mathrm{~s}$, this study assumed that PGA in the GMPE corresponded to $T=0.04 \mathrm{~s}$ to better constrain the FAS at high frequencies. We judged $0.04 \mathrm{~s}$ to be most appropriate, as the majority of the data used to develop the McVerry et al. (2006) GMPE had a sampling rate of $50 \mathrm{~Hz}$ and hence a Nyquist frequency of $25 \mathrm{~Hz}$. $f_{e}$ and $f_{x}$ were picked individually on each spectrum, with $f_{x} \leq 20 \mathrm{~Hz}$. Figure $10 \mathrm{a}-\mathrm{g}$ shows $\kappa_{0, \text { IRVT }}$ estimates from the Bradley (2013) GMPE, for the seven sites in this study. Triangles, circles, and crosses correspond to the $M_{\mathrm{w}} 6.5,6$, and 5.5 scenarios, respectively. There is no apparent dependence with distance or magnitude for the rock sites, whereas for the stiff soil site, HVSC, $\kappa_{0, \text { IRVT }}$ decreases slightly as magnitude increases. Figure $10 \mathrm{~h}$ and $10 \mathrm{i}$ shows $\kappa_{0, \mathrm{IRVT}}$ from the McVerry et al. (2006) GMPE, for NZS 1170.5:2004 class B and class C sites, respectively (Standards New Zealand, 2004), using the same magnitude and distance scenarios. $\kappa_{0, \mathrm{IRVT}}$ is higher for McVerry et al. (2006) than for Bradley (2013). However, these values are likely to be influenced by our assumption that PGA in the McVerry et al. (2006) model is equivalent to $T=0.04 \mathrm{~s}$, as the choice of spectral period would significantly change the slope. There is also an increase in $\kappa_{0, \text { IRVT }}$ at small distances, especially for the smaller magnitude scenarios. This may be because at the time of the development of the McVerry et al. (2006) GMPE, there were a lack of New Zealand data for distances less than $10 \mathrm{~km}$, and the dataset was therefore supplemented with foreign PGA data. The highfrequency range of the McVerry et al. (2006) model appears to be too limited to obtain an accurate estimate of $\kappa_{0, \text { IRVT }}$; however, it is unlikely that the GMPE was ever intended to be used in this way. Given that we are pushing the McVerry et al. (2006) model somewhat beyond its limits, the Bradley (2013) GMPE may be a more reliable representation of the highfrequency characteristics of the Canterbury data. 

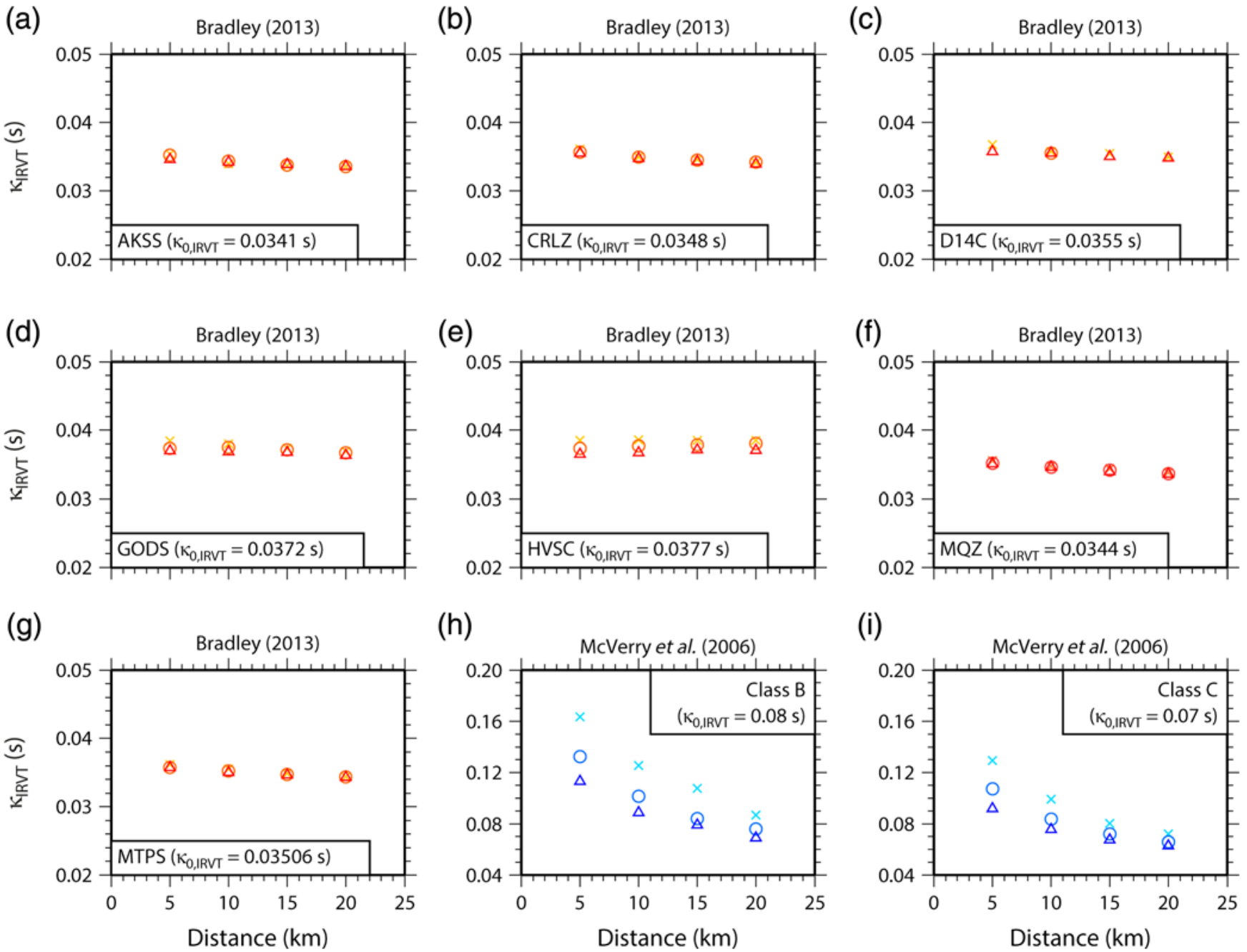

Figure 10. $\quad \kappa_{\mathrm{IRVT}}$ for magnitude, distance, and site scenarios using (a-g) the Bradley (2013) and (h, i) the McVerry et al. (2006) GMPEs. Triangles, circles, and crosses correspond to $M_{\mathrm{w}} 6.5,6$, and 5.5 scenarios, respectively. The Bradley (2013) GMPE uses $V_{S 30}$ and $Z_{1.0}$ as the site term predictor variables, whereas McVerry et al. (2006) uses NZS1170.5:2004 site classifications (see Table 1 for the site data of each of the seven stations). Please note the different scale on (h) and (i). The color version of this figure is available only in the electronic edition.

\section{Comparison of $\kappa_{0, \mathrm{AS}}$ and $\kappa_{0, \mathrm{IRVT}}$}

To compare the $\kappa_{0, \mathrm{IRVT}}$ values with the $\kappa_{0, \mathrm{AS}}$ estimates from the previous sections, Figure 11 plots both against $V_{S 30}$ for the seven stations in this study. Table 3 shows the values for each station. In general, $\kappa_{0, \text { IRVT }}$ from the Bradley (2013) GMPE matches well with the $\kappa_{0, A S}$ values, mostly within one standard deviation of the mean $\kappa_{0, A S}$. There appears to be a slight correlation between $\kappa_{0, \text { IRVT }}$ and $V_{S 30}$; however, the trend of $\kappa_{0, \mathrm{IRVT}}$ with $V_{S 30}$ has a significantly shallower slope than the general trend of $\kappa_{0, \text { AS }}$ with $V_{S 30}$. This suggests that current GMPEs do not scale adequately with $\kappa$, possibly due to their form. A small change in $\kappa$ may significantly modify the high-frequency shape of an FAS, however, GMPEs are typically fitted to response spectra (rather than FAS), in which the high frequencies are smoothed and hence less sensitive to $\kappa$. Therefore, to better model high frequencies in GMPEs, it may be beneficial to empirically fit the FAS, then compute a response spectrum using RVT (e.g., Bora et al., 2014).

\section{Discussion}

The most significant finding from our analysis is the apparent decrease in $\kappa_{0, \mathrm{AS}}$ with large ground-motion amplitudes. Although the physical mechanism (or mechanisms) causing this trend is currently unclear, the potential implications for hazard assessments at critical installations are large. These facilities are often designed to resist events with very low probabilities of occurance but high ground-motion intensities. Direct measurements of $\kappa$ are predominantly obtained from low-intensity earthquake records that are not of engineering interest, then applied to predict ground motion for high-intensity events, either through host-to-target adjustments, stochastic simulations, or GMPEs. This process is invalid if high-intensity $\kappa$ values are different from low-intensity $\kappa$ values, as our findings may suggest. Given its importance for the earthquake-resistant design of critical facilities, future research should focus on the variation of $\kappa$ with ground-motion 


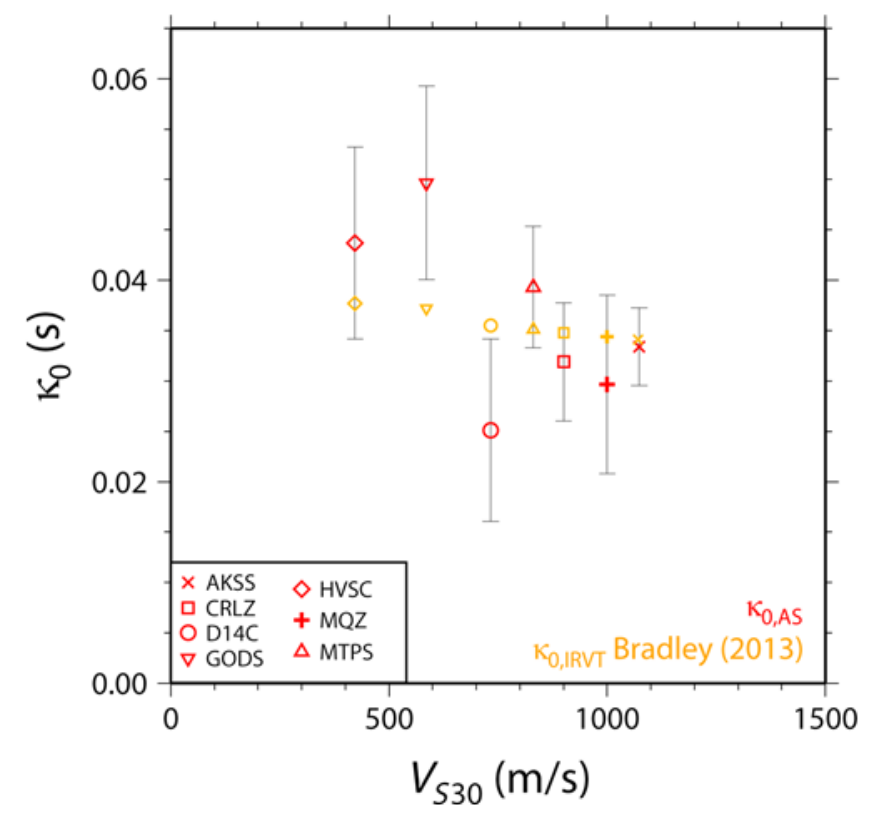

Figure 11. Comparison of $\kappa_{0, \mathrm{AS}}$ (mean and standard deviation) and $\kappa_{0, \text { IRVT }}$ from the Bradley (2013) GMPE, plotted against $V_{S 30}$. The color version of this figure is available only in the electronic edition.

amplitude. The $\kappa_{0, \mathrm{AS}}-\mathrm{PGA}$ correlation we present here is still relatively weak and requires further analysis with a larger dataset of high-intensity rock-site recordings.

The variation in $\kappa_{0, \mathrm{AS}}$ with ground-motion amplitude also means that the minimum magnitude recommendations for estimating $\kappa_{\mathrm{AS}}$ in Table 2 are guidelines for measuring low-intensity $\kappa_{\mathrm{AS}}$ only. The recommendations have been proposed to prevent trade-off between source parameters and $\kappa_{\mathrm{AS}}$ in future studies. Events larger than our minimum magnitude recommendations can still be used to calculate low-intensity $\kappa_{\mathrm{AS}}$; however, they may overestimate high-intensity $\kappa_{\mathrm{AS}}$.

A further recommendation of this study is an orientation-independent definition of $\kappa_{\mathrm{AS}}$, to average over possible high-frequency 2D site effects. Such effects may be significant at sites with strong $2 \mathrm{D}$ geological structures, with $\kappa_{0, \mathrm{AS}}$ varying by up to $25 \%$ depending on the horizontal component orientation. Using an orientation-independent definition for $\kappa_{\mathrm{AS}}$ is more robust than calculating $\kappa_{\mathrm{AS}}$ as the mean from two arbitrarily orientated components, and therefore it can be used to compute a more stable mean as well as an estimate of uncertainty due to component orientation. Note, however, that the variation due to component orientation is still less than the standard deviation of $\kappa_{0, \mathrm{AS}}$ at each station, that is, despite our attempts to reduce and understand the scatter in $\kappa_{\mathrm{AS}}$, the observed variability is still very high at all stations. Future research should focus on further understanding the physical mechanisms behind $\kappa$ and identifying other sources of scatter contributing to the variation in $\kappa$.

In addition to analyzing the scatter in $\kappa_{\mathrm{AS}}$ measurements, this study also compares results from Christchurch with the native $\kappa_{0}$ values of local GMPEs. $\kappa_{0, \mathrm{IRVT}}$ from the Bradley
Table 3

$\kappa_{0}$ Results for the Seven Sites in This Study

\begin{tabular}{lccc}
\hline Station & $\begin{array}{c}\text { Mean } \\
\kappa_{0, \mathrm{AS}}(\mathrm{s})\end{array}$ & $\begin{array}{c}\text { Standard Deviation } \\
\text { of } \kappa_{0, \mathrm{AS}}(\mathrm{s})\end{array}$ & $\begin{array}{c}\kappa_{0, \mathrm{IRVT}}(\mathrm{s}) \text { from } \\
\text { Bradley }(2013)\end{array}$ \\
\hline AKSS & 0.0334 & 0.0039 & 0.0341 \\
CRLZ & 0.0319 & 0.0059 & 0.0348 \\
D14C & 0.0251 & 0.0091 & 0.0355 \\
GODS & 0.0497 & 0.0096 & 0.0372 \\
HVSC & 0.0437 & 0.0095 & 0.0377 \\
MQZ & 0.0297 & 0.0089 & 0.0344 \\
MTPS & 0.0393 & 0.0060 & 0.0351 \\
\hline
\end{tabular}

(2013) GMPE is relatively independent of distance and $V_{S 30}$, indicating that it is mostly decoupled from these effects. Although this suggests that the GMPE is smoothing the highfrequency effect, it also means that the Bradley (2013) model, and therefore the Chiou and Youngs (2008) model, on which the Bradley (2013) model is based, are good candidate GMPEs for $\kappa$ adjustments. $\kappa_{0, \mathrm{AS}}$ from Christchurch rock sites are similar to $\kappa_{0, \text { IRVT }}$ from Bradley (2013), therefore this model is likely to give relatively reliable predictions for short-period rock motions in Christchurch.

\section{Data and Resources}

We acknowledge the New Zealand GeoNet project (www .geonet.org.nz, last accessed September 2013) and its sponsors, the Earthquake Commission (EQC), GNS Science, and Land Information New Zealand (LINZ), for providing the data used in this study. Signal processing benefited greatly from the use of Seismic Analysis Code (SAC; Goldstein and Snoke, 2005; www.iris.edu/software/sac, last accessed February 2013), and figures were created using Generic Mapping Tools (Wessel and Smith, 1998; http://gmt .soest.hawaii.edu, last accessed June 2013). We thank Graeme McVerry for kindly providing Fortran scripts to generate response spectra for the McVerry et al. (2006) GMPE. Response spectra for the Bradley (2013) GMPE were generated using code from https://sites.google.com/site/brendonabradley/ research/ground-motion-prediction (last accessed July 2013). The software used to perform the IRVT calculations is publically available from https://github.com/arkottke/irvt (last accessed June 2013; Kottke and Rathje, 2008). Geophysical software Geopsy and Dinver (Wathelet, 2008; www.geopsy .org, last accessed May 2013) were used to, respectively, calculate and invert dispersion curves to obtain $V_{S}$ profiles.

\section{Acknowledgments}

The orientation-independent definition of $\kappa$ was inspired by the work of Boore et al. (2006). The authors would like to thank N. Abrahamson, P.-Y. Bard, S. Iai, and A. Kottke for fruitful discussions and suggestions. We are grateful for the assistance of L. Wotherspoon, L. Storie, and S. Garambois in collecting and analyzing geophysical data for the $V_{S}$ profiles. C.V.H. is funded by a University of Auckland Doctoral Scholarship, and O.J.K. is funded by the French SIGMA project. The authors would like to thank F. Cotton for reading an early version of this manuscript and providing 
useful comments. This work greatly benefited from the thoughtful reviews of two anonymous reviewers.

\section{References}

Aki, K. (1987). Magnitude-frequency relation for small earthquakes: A clue to the origin of $f_{\max }$ of large earthquakes, J. Geophys. Res. 92, no. B2, 1349-1355.

Al Atik, L., A. Kottke, N. Abrahamson, and J. Hollenback (2014). Kappa ( $\kappa)$ scaling of ground motion prediction equations using inverse random vibration theory approach, Bull. Seismol. Soc. Am. 104, no. 1, doi: 10.1785/0120120200.

Anderson, J. G. (1991). A preliminary descriptive model for the distance dependence of the spectral decay parameter in southern California, Bull. Seismol. Soc. Am. 81, no. 6, 2186-2193.

Anderson, J. G., and S. E. Hough (1984). A model for the shape of the Fourier amplitude spectrum of acceleration at high frequencies, Bull. Seismol. Soc. Am. 74, no. 5, 1969-1993.

Bannister, S., and K. Gledhill (2012). Evolution of the 2010-2012 Canterbury earthquake sequence, New Zeal. J. Geol. Geophys. 55, no. 3, 295-304.

Bannister, S., B. Fry, M. Reyners, J. Ristau, and H. Zhang (2011). Fine-scale relocation of aftershocks of the 22 February $M_{\mathrm{w}} 6.2$ Christchurch earthquake using double-difference tomography, Seismol. Res. Lett. 82, no. 6, 839-845.

Biro, Y., and P. Renault (2012). Importance and impact of host-to-target conversions for ground motion prediction equations in PSHA, in 15th World Conference on Earthquake Engineering, Lisbon, Portugal, 24-28 September 2012.

Boore, D. M. (2003). Simulation of ground motion using the stochastic method, Pure Appl. Geophys. 160, nos. 3/4, 635-676.

Boore, D. M., J. Watson-Lamprey, and N. A. Abrahamson (2006). Orientation-independent measures of ground motion, Bull. Seismol. Soc. Am. 96, no. 4A, 1502-1511.

Bora, S. S., F. Scherbaum, N. Kuehn, and P. Stafford (2014). Fourier spectral- and duration models for the generation of response spectra adjustable to different source-, propagation-, and site conditions, Bull. Earthq. Eng. 12, no. 1, 467-493.

Bradley, B. A. (2013). A New Zealand specific pseudospectral acceleration ground motion prediction equation for active shallow crustal earthquakes based on foreign models, Bull. Seismol. Soc. Am. 103, no. $3,1801-1822$.

Campbell, K. W. (2003). Prediction of strong ground motion using the hybrid empirical method and its use in the development of groundmotion (attenuation) relations in eastern North America, Bull. Seismol. Soc. Am. 93, no. 3, 1012-1033.

Chandler, A., N. Lam, and H. Tsang (2006). Near-surface attenuation modelling based on rock shear-wave velocity profile, Soil Dyn. Earthq. Eng. 26, no. 11, 1004-1014.

Chiou, B., and R. Youngs (2006). Chiou and Youngs PEER-NGA empirical ground motion model for the average horizontal component of peak acceleration and pseudo-spectral acceleration for spectral periods of 0.01 to 10 seconds, Interim Report Issued for USGS Review.

Chiou, B., and R. R. Youngs (2008). An NGA model for the average horizontal component of peak ground motion and response spectra, Earthq. Spectra 24, no. 1, 173-215.

Cotton, F., F. Scherbaum, J. J. Bommer, and H. Bungum (2006). Criteria for selecting and adjusting ground-motion models for specific target regions: Application to Central Europe and rock sites, J. Seismol. 10, no. 2, 137-156.

Dimitriu, P., N. Theodulidis, P. Hatzidimitriou, and A. Anastasiadis (2001) Sediment non-linearity and attenuation of seismic waves: A study of accelerograms from Lefkas, western Greece, Soil Dyn. Earthq. Eng. 21, no. 1, 63-73.

Douglas, J., H. Bungum, and F. Scherbaum (2006). Ground-motion prediction equations for southern Spain and southern Norway obtained using the composite model perspective, J. Earthq. Eng. 10, no. 1, 33-72.

Douglas, J., P. Gehl, L. F. Bonilla, and C. Gélis (2010). A $\kappa$ model for mainland France, Pure Appl. Geophys. 167, no. 11, 1303-1315.

Edwards, B., and D. Fäh (2013). Measurements of stress parameter and site attenuation from recordings of moderate to large earthquakes in Europe and the Middle East, Geophys. J. Int. 194, no. 2, 1190-1202.

Edwards, B., D. Fäh, and D. Giardini (2011). Attenuation of seismic shear wave energy in Switzerland, Geophys. J. Int. 185, no. 2, 967-984.

Faccioli, E., A. Tagliani, and R. Paolucci (1989). Effects of wave propagation in random earth media on the seismic radiation spectrum, in Structural Dynamics and Soil-Structure Interaction, A. Cakmak and I. Herrera (Editors), Proceedings of the 4th International Conference on Soil Dynamics and Earthquake Engineering, Computational Mechanics Publications, Southampton, 197-208.

Gasparini, D. A., and E. H. E. J. Vanmarcke (1976). Simulated Earthquake Motions Compatible with Prescribed Response Spectra, Department of Civil Engineering, Research report R76-4, Massachusetts Institute of Technology.

Gentili, S., and G. Franceschina (2011). High frequency attenuation of shear waves in the southeastern Alps and northern Dinarides, Geophys. J. Int. 185, no. 3, 1393-1416.

Goldstein, P., and A. Snoke (2005). SAC availability for the IRIS community, Incorporated Institutions for Seismology Data Management Center Electronic Newsletter, Vol. 7, 1-6.

Gonella, J. (1972). A rotary-component method for analysing meteorological and oceanographic vector time series, in Deep Sea Research and Oceanographic Abstracts, Vol. 19, 833-846.

Haines, A. J. (1981). A local magnitude scale for New Zealand earthquakes, Bull. Seismol. Soc. Am. 71, no. 1, 275-294.

Hanks, T. C. (1982). $f_{\max }$, Bull. Seismol. Soc. Am. 72, no. 6A, 1867-1879.

Kilb, D., G. Biasi, J. Anderson, J. Brune, Z. Peng, and F. L. Vernon (2012). A comparison of spectral parameter kappa from small and moderate earthquakes using southern California ANZA seismic network data, Bull. Seismol. Soc. Am. 102, no. 1, 284-300.

Kottke, A. R., and E. M. Rathje (2008). Technical manual for STRATA, Report 2008/10, Pacific Earthquake Engineering Research (PEER) Center, Berkeley, California.

Ktenidou, O.-J., F. Cotton, N. Abrahamson, and J. Anderson (2014). Taxonomy of $\kappa$ : A review of definitions and estimation approaches targeted to applications, Seismol. Res. Lett. 85, no. 1, 135-146.

Ktenidou, O.-J., C. Gélis, and L.-F. Bonilla (2013). A study on the variability of kappa $(\kappa)$ in a borehole: Implications of the computation process, Bull. Seismol. Soc. Am. 103, no. 2A, 1048-1068.

Laurendeau, A., F. Cotton, O.-J. Ktenidou, L.-F. Bonilla, and F. Hollender (2013). Rock and stiff soil site amplification: Dependency on $V_{S 30}$ and kappa $\left(\kappa_{0}\right)$, Bull. Seismol. Soc. Am. 103, no. 6, 3131-3148.

McVerry, G. H., J. X. Zhao, N. A. Abrahamson, and P. G. Somerville (2006). New Zealand acceleration response spectrum attenuation relations for crustal and subduction zone earthquakes, Bull. New Zeal. Soc. Earthq. Eng. 39, no. 1, 1-58.

Motazedian, D., and G. M. Atkinson (2005). Stochastic finite-fault modeling based on a dynamic corner frequency, Bull. Seismol. Soc. Am. 95, no. 3, 995-1010.

Oth, A., and A. Kaiser (2013). Stress release and source scaling of the 20102011 Canterbury, New Zealand, earthquake sequence from spectral inversion of ground motion data, Pure Appl. Geophys. 1-16, doi: 10.1007/s00024-013-0751-1.

Papageorgiou, A. S., and K. Aki (1983). A specific barrier model for the quantitative description of inhomogeneous faulting and the prediction of strong ground motion. I. Description of the model, Bull. Seismol. Soc. Am. 73, no. 3, 693-722.

Parolai, S., and D. Bindi (2004). Influence of soil-layer properties on $\kappa$ evaluation, Bull. Seismol. Soc. Am. 94, no. 1, 349-356.

Purvance, M. D., and J. G. Anderson (2003). A comprehensive study of the observed spectral decay in strong-motion accelerations recorded in Guerrero, Mexico, Bull. Seismol. Soc. Am. 93, no. 2, 600-611. 
Rathje, E., A. Kottke, and C. Ozbey (2005). Using inverse random vibration theory to develop input Fourier amplitude spectra for use in site response, in 16th International Conference on Soil Mechanics and Geotechnical Engineering: TC4 Earthquake Geotechnical Engineering Satellite Conference, Osaka, Japan, 12-16 September 2005, 160-166.

Rebollar, C. J. (1990). Estimates of shallow attenuation of the San Miguel fault, Baja California, Bull. Seismol. Soc. Am. 80, no. 3, 743-746.

Ristau, J. (2013). Update of regional moment tensor analysis for earthquakes in New Zealand and adjacent offshore regions, Bull. Seismol. Soc. Am. 103, no. 4, 2520-2533.

Scasserra, G., J. P. Stewart, P. Bazzurro, G. Lanzo, and F. Mollaioli (2009). A comparison of NGA ground-motion prediction equations to Italian data, Bull. Seismol. Soc. Am. 99, no. 5, 2961-2978.

Silva, W., D. Darragh, N. Gregor, G. Martin, N. Abrahamson, and C. Kircher (1998). Reassessment of site coefficients and near fault factors for building code provisions, Program Element: II, 98-HQGR-1010, Report to US Geological Survey (USGS) Reston, Virginia.

Standards New Zealand (2004). Structural Design Actions Part 5: Earthquake Actions, Department of Building and Housing, Wellington, New Zealand.

Tatsuoka, F., H. Di Benedetto, T. Enomoto, S. Kawabe, and W. Kongkitkul (2008). Various viscosity types of geomaterials in shear and their mathematical expression, Soils Found. 48, no. 1, 41-60.

Tsai, C.-C. P., and K.-C. Chen (2000). A model for the high-cut process of strong-motion accelerations in terms of distance, magnitude, and site condition: An example from the SMART 1 array, Lotung, Taiwan, Bull. Seismol. Soc. Am. 90, no. 6, 1535-1542.

Van Houtte, C., S. Drouet, and F. Cotton (2011). Analysis of the origins of $\kappa$ (kappa) to compute hard rock to rock adjustment factors for GMPEs, Bull. Seismol. Soc. Am. 101, no. 6, 2926-2941.

Van Houtte, C., O. Ktenidou, T. Larkin, and A. Kaiser (2012). Reference stations for Christchurch, Bull. New Zeal. Soc. Earthq. Eng. 45, no. 4, 184-195.

Wathelet, M. (2008). An improved neighborhood algorithm: Parameter conditions and dynamic scaling, Geophys. Res. Lett. 35, no. 9, doi: 10.1029/2008GL033256.
Wells, D. L., and K. J. Coppersmith (1994). New empirical relationships among magnitude, rupture length, rupture width, rupture area, and surface displacement, Bull. Seismol. Soc. Am. 84, no. 4, 974-1002.

Wessel, P., and W. H. Smith (1998). New, improved version of Generic Mapping Tools released, Eos Trans. AGU 79, no. 47, 579-579.

Wood, C. M., B. R. Cox, L. M. Wotherspoon, and R. A. Green (2011). Dynamic site characterization of Christchurch strong motion stations, Bull. New Zeal. Soc. Earthq. Eng. 44, no. 4, 195-204.

Department of Civil Engineering

Faculty of Engineering

The University of Auckland

Private Bag 92019

Auckland Mail Centre

Auckland 1142, New Zealand

(C.V.H., T.L.)

ISTerre

Université Joseph Fourier

Université de Grenoble 1

CNRS BP53

38041 Grenoble Cedex 9, France

(O.-J.K.)

GNS Science

PO Box 30-368

Lower Hutt 5040, New Zealand

(C.H.)

Manuscript received 22 October 2013; Published Online 15 July 2014 